\title{
Systematic Integrated Process Design and Control of Reactive Distillation Processes Involving Multi-elements
}

\author{
Mansouri, Seyed Soheil; Sales-Cruz, Mauricio; Huusom, Jakob Kjøbsted; Gani, Rafiqul
}

Published in:

Chemical Engineering Research \& Design

Link to article, DOI:

10.1016/j.cherd.2016.07.010

Publication date:

2016

Document Version

Peer reviewed version

Link back to DTU Orbit

Citation (APA):

Mansouri, S. S., Sales-Cruz, M., Huusom, J. K., \& Gani, R. (2016). Systematic Integrated Process Design and Control of Reactive Distillation Processes Involving Multi-elements. Chemical Engineering Research \& Design, 115(Part B), 348-364. https://doi.org/10.1016/j.cherd.2016.07.010

\section{General rights}

Copyright and moral rights for the publications made accessible in the public portal are retained by the authors and/or other copyright owners and it is a condition of accessing publications that users recognise and abide by the legal requirements associated with these rights.

- Users may download and print one copy of any publication from the public portal for the purpose of private study or research.

- You may not further distribute the material or use it for any profit-making activity or commercial gain

- You may freely distribute the URL identifying the publication in the public portal 


\section{Accepted Manuscript}

Title: Systematic Integrated Process Design and Control of

Reactive Distillation Processes Involving Multi-elements

Author: Seyed Soheil Mansouri Mauricio Sales-Cruz Jakob

Kjøbsted Huusom Rafiqul Gani

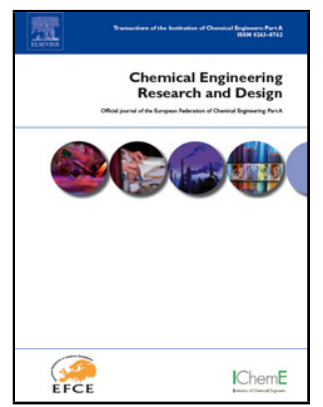

PII:

S0263-8762(16)30189-7

DOI:

http://dx.doi.org/doi:10.1016/j.cherd.2016.07.010

Reference:

CHERD 2334

To appear in:

Received date: $\quad 1-4-2016$

Revised date: $\quad 30-6-2016$

Accepted date: $\quad$ 14-7-2016

Please cite this article as: Mansouri, S.S., Sales-Cruz, M., Huusom, J.K., Gani, R.,Systematic Integrated Process Design and Control of Reactive Distillation Processes Involving Multi-elements, Chemical Engineering Research and Design (2016), http://dx.doi.org/10.1016/j.cherd.2016.07.010

This is a PDF file of an unedited manuscript that has been accepted for publication. As a service to our customers we are providing this early version of the manuscript. The manuscript will undergo copyediting, typesetting, and review of the resulting proof before it is published in its final form. Please note that during the production process errors may be discovered which could affect the content, and all legal disclaimers that apply to the journal pertain. 


\section{Highlights:}

- Integrated computer aided framework for integrated process design and control

3 - The framework has been applied on multi-element RDC

4 - Process design at the maximum driving force has the best controllability

5

- Similar methods for designing non-reactive multi-component distillation are used

6 
Step 1: Process Design:

N Design a ltema tives that

match design targets to separate A from B

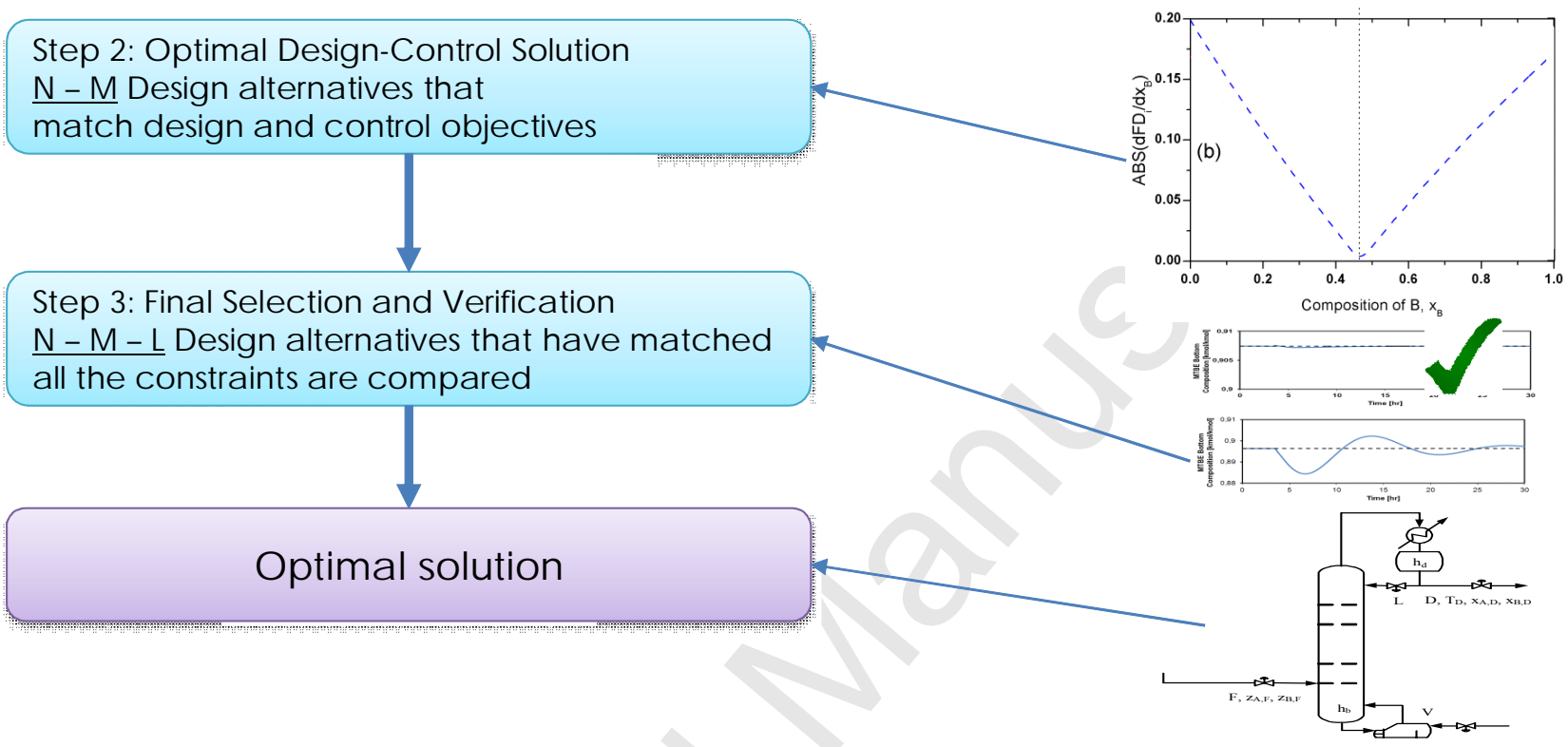

2 


\title{
Systematic Integrated Process Design and Control of Reactive Distillation Processes Involving Multi-elements
}

\author{
Seyed Soheil Mansouri ${ }^{1}$, Mauricio Sales-Cruz ${ }^{2}$, Jakob Kjøbsted Huusom ${ }^{1}$, Rafiqul Gani ${ }^{1, \uparrow}$ \\ ${ }^{1}$ Department of Chemical and Biochemical Engineering, Technical University of Denmark, Søltofts Plads, Building \\ 229, DK-2800 Kongens Lyngby, Denmark \\ ${ }^{2}$ Departamento de Procesos y Tecnología, Universidad Autónoma Metropolitana-Cuajimalpa, Avenida Vasco de \\ Quiroga No.4871, Colonia Santa Fe, Delegación Cuajimalpa de Morelos, Ciudad de México, C.P. 05300, Mexico \\ ${ }^{\dagger}$ To whom correspondence should be addressed. E-mail: rag@kt.dtu.dk; Tel.: +45 45252882; Fax: +45 45932906
}

\begin{abstract}
In this work, integrated process design and control of reactive distillation processes that involve multiple elements (more than two) is addressed through a computer-aided hierarchical decomposition-based framework. Multiple elements are encountered for reactive systems when four or more compounds (including inert compounds) are encountered. The reactive distillation design methods and tools which are similar in concept to design of binary non-reactive distillations and binary reactive distillations are used for design of multi-element reactive distillation processes, such as driving force approach. The methods that are used in this work are based on equivalent binary element concept. This concept provides the representation of a multi-element system in terms of two key elements, light key and heavy key elements. First, the reactive distillation column is designed using the equivalent binary element driving force approach. Next, through analytical, steady-state and closed-loop dynamic analysis it is verified that the control structure, disturbance rejection and energy requirement of the reactive distillation column is better than any other operation point that is not at the maximum driving force. Furthermore, it is shown that the design at the maximum driving force can be both controlled using simple controllers such as PI as well as advanced controllers such as MPC.
\end{abstract}

Keywords: Reactive Distillation; Process Design; Process Control; Driving Force; Computer-Aided Framework, Multi-element systems

\section{Introduction}

A common practice in resolving process design and control issues is to consider them as independent problems, meaning that: first process design is performed with economic steady-state objectives; next controller design is carried out considering process dynamics constraints and control objectives. However, this sequential approach may results in conflicting process design and control objectives for the chemical processes. Some of this trade-offs between design and control that is not addressed through this approach is infeasible operating points (set-points for controlled and/or manipulated variables), process over design and infeasible control structures. Therefore, a robust, feasible and reliable performance is not always guaranteed (Lenhoff and Morari, 1982; Ricardez-Sandoval et al., 2009; Seferlis and Georgiadis, 2004).

An important issue in process design and control is how in the early stages of process design, decisions related to process design can be made in such a way that the process is economically optimal and at the same time can be operated with feasible dynamic characteristics. To tackle this challenge, methodologies that systematically address the optimal design and control simultaneously are of great importance. Integrated process design and control is an alternative which is widely accepted to obtain economically 
attractive, dynamically feasible, and flexible processes. This simultaneous approach has been given a wide attention in the literature and reviewed extensively (Huusom, 2015; Mehta and Ricardez-Sandoval, 2016; Ricardez-Sandoval et al., 2009; Yuan et al., 2012). This simultaneous synthesis approach provides optimal/near optimal operation and more efficient control of chemical processes. Most importantly, it is possible to identify and eliminate potentially promising design alternatives that may have controllability problems (Alvarado-Morales et al., 2010).

There is an increasing interest in application of intensified and multi-functional processes in chemical industry (Nikačević et al., 2012). Several applications of process intensification principles are realized so far on an industrial scale including reactive distillation, micro-reactors, rotating packed bed systems, etc. However, reactive distillation with already over 150 industrial applications is one of the most successful intensified processes on an industrial scale (Harmsen, 2007).

Reactive distillation column (RDC) is a unit operation in which separation and reaction take place in a single operation, thus making it a multi-functional unit operation. Due to its very successful application in the industry it has attracted considerable amount of research both from academia and industry (Tuchlenski et al., 2001). It offers substantial advantages, such as higher reaction rate and selectivity (Lee et al., 2010), avoidance of azeotropes and reduced energy consumption as well as solvent usage (Babi et al., 2014; Mansouri et al., 2013). However, it must be noted that as a result of integration of functions/operations into a single unit operation, the control and operation of the RDC poses a challenge due to the loss in degrees of freedom.

Sneesby et al. (1999) explored the interactions between design and control where they focused on control schemes for reactive distillation taking into account effect of the principal operating parameters on the reactant conversion. For this purpose, they proposed a standard regulatory control system for an ETBE reactive distillation column where the reboiler duty (or the bottoms draw rate) to control the bottoms composition inferred via a stripping section temperature was used. They found their structure to be closed-loop stable, unlike many other control schemes which used other temperatures (e.g. the reboiler temperature) to infer the ether purity. However, the scheme their reported had a major deficiency which was its inability to control the composition to a set-point. Chung et al. (2015) addressed design and

control of reactive distillation process for esterification of levulinic acid and n?butanol. They performed

sensitivities of some design variables such as feed ratio of raw materials and operating pressure for economic production of n-butyl levulinate. They obtained the optimal steady-state design through total annual cost analysis using iterative optimization. Next, they proposed two feasible control structures which both can reject throughput disturbances sufficiently well; however, they were only able to handle feed composition disturbances.

The methodologies developed for integrated process design and control are categorized as those based on formulation and solution of a dynamic optimization problem (to be called dynamic optimization approach) and those based on formulating and solving a set of hierarchical sub-problems (to be called the decomposition approach). In the dynamic optimization approach, the continuous variables are linked with 
design variables (such as, flow rates, heat duties) and process variables (temperatures, pressures, compositions), while binary (decision) variables are used to model logical decisions such as whether to choose between different possible flowsheet structures and/or controller structures. In the integrated process design-control context, the variables are considered in the process model such that they represent both steady-state and dynamic behavior of the problem, which in this case the optimization problem is referred to as mixed integer dynamic optimization (MIDO). Bahri et al. (1997) proposed an integrated approach based on the dynamic mixed-integer nonlinear-programming problem that consists of two stages in each iteration of the algorithm. Therefore, the effect of disturbances on the process design and operation, as well as its ideal performance, under a variety of control schemes can be estimated. Bansal et al. (2003) proposed new formulations and algorithms for solving MIDO problems. These algorithms are based on decomposition into primal, dynamic optimization and master, mixed-integer linear programming sub-problems. Flores-Tlacuahuac and Biegler (2007) developed an algorithm based on the transformation of the MIDO problem into a mixed-integer nonlinear programming (MINLP) program. In this approach, both the manipulated and controlled variables are discretized using a simultaneous dynamic optimization approach. They also developed three MINLP formulations based on a nonconvex formulation, the conventional Big-M formulation and generalized disjunctive programming (GDP).

The main idea in the decomposition-based approach is to decompose the integrated process design and control problem into an ordered set of sub-problems. Each sub-problem, except the last one, requires only the solution of a subset from the original constraints set. The final sub-problem contains the objective function and the remaining constraints. In this way, the solution of the decomposed set of sub-problems is equivalent to that of the original optimization problem. The advantage is a more flexible solution approach together with relatively easy to solve sub-problems. Recently, a decomposition-based optimization approach is proposed to tackle the integration of process design and controller design for single reactor, single separator and reactor-separator-recycle processes (Alvarado-Morales et al., 2010; Hamid et al., 2010). The main merit of this proposed solution strategy is, based on the reverse approach and thermodynamic-process insights (for example attainable region (Hildebrandt and Glasser, 1990) and driving force approach (Gani and Bek-Pedersen, 2000)) to decompose the whole framework into sequential hierarchical sub-problems. The decomposition approach offers an effective solution strategy and several applications of this approach have been reported in the literature in solving different optimization problems in chemical engineering (for example, design of optimal solvents and solvent mixtures (Karunanithi et al., 2005), process synthesis and intensification (Mansouri et al., 2013) and process control (Hamid et al, 2010). Note however, recently, Sharifzadeh (Sharifzadeh, 2013) has extensively reviewed the methods and current state-of-the-art for integrated process design and control.

Here, only a few decomposition algorithms in the area of integration of process design and control that have been proposed are reviewed. Mohideen et al. (1996), proposed a unified decomposition-based process design framework for obtaining integrated process and control systems design based on a dynamic mathematical model describing the process, including path constraints, interior and end-point constraints, a model that describes uncertain parameters and time-varying disturbances and a set of process design and control alternatives. Kookos and Perkins (2001) developed an algorithm based on the systematic generation of lower and upper bounds on the best achievable dynamic economics of the combined plant to effectively reduce the size of the search space. Sanchez-Sanchez and RicardezSandoval (2013) proposed a methodology that includes process synthesis and control structure decisions for the optimal process and control design of dynamic systems under uncertainty. The key feature 
introduced by this method is the simultaneous evaluation of dynamic flexibility and feasibility for optimal process synthesis and control structure design. Trainor et al. (2013) developed a new simultaneous design and control methodology that accounts for structural decisions in the analysis. Their proposed approach involves an iterative decomposition framework that includes a robust feasibility analysis and a robust asymptotic stability test. Their results illustrated through a case study indicates that their methodology is a suitable tool to simultaneously design and control systems that can maintain dynamically feasibility and asymptotically stability in the presence of critical time-dependent realizations in the disturbances. Pistikopoulos and Diangelakis (2015), raised the concern that while significant progress has been achieved over the years at the moment there is not a generally accepted methodology and/or "protocol" for integrated process design, control and scheduling, also currently, there is not a commercially available software [or even in a prototype form] system to fully support such an activity. They presented the foundations for such an integrated framework and especially a software platform that enables such integration based on research developments. They particularly emphasized on PAROC, a prototype software system which allows for the representation, modeling and solution of integrated design, scheduling and control problems.

The application of model predictive control (MPC) has been scarcely addressed in the literature on the integrated process design and control. Note however, there are a few works that have looked at this in the literature which are also briefly reviewed here. Francisco et al. (2011) proposed a methodology for the simultaneous design of processes with linear MPC, providing simultaneously the plant dimensions, the control system parameters and a steady state working point. They illustrated the application of their methodology on the activated sludge process of a wastewater treatment plant. Bahakim and Ricardezsandoval (2014) proposed a methodology based on stochastic simultaneous design and control for chemical processes under uncertainty. They also proposed an optimization framework to obtain a feasible and stable process design in presence of stochastic disturbances. Advanced model-based control schemes such as MPC were also used. Their stochastic-based methodology represents a practical approach to address the integration of design and control while using advanced model-based control strategies such as MPC.

In this work, we have extended the application of our methodology (Mansouri et al., 2016a, 2015) to integrated process design and control of reactive distillation processes that are represented with more than two elements through a systematic hierarchical approach implemented through a computer-aided framework. The concepts, theory and derivations related to the integrated process design and control of reactive distillation processes are already established in a previous work from the same authors (Mansouri et al., 2016a). The framework consists of five hierarchical steps by which (i) the objectives and design targets are set, (ii) the number of elements in the system is identified, (iii) the key elements representing the multi-element system are identified (iv) the reactive distillation column is designed and the control structure is determined, and (v) the designed operation is verified by rigorous dynamic analysis. Note that, the application of MPC has been also demonstrated on an integrated process design-control solution for a multi-element reactive distillation.

\section{Multi-element systems}

The element-based approach is a method of identifying the minimum number of elements that can represent a multi-component reacting system. This method satisfies the atom balance for all the compounds that are present in the reacting system including the inert ones. For example, in case of two 
reactants with molecular structure M1 and M2, and an inert compound M3, it is always true (given that there is no stoichiometric constraint in the reaction such as the requirement of electrical neutrality in a system of electrolytes) that the product must have the molecular structure M1M2. Therefore, the four component system has three elements with one reaction where the inert compound has remained invariant as an independent element. This approach was first proposed by Michelsen (Michelsen, 1994) to facilitate the calculation of element composition in vapor and liquid phases which is termed as the solution to the chemical-physical equilibrium (CPE). This simultaneous solution approach to the CPE problem is essential to determine and predict the limits of reaction conversion and separation in a reaction-separation operation (Pérez-Cisneros et al., 1997). One of the main features of this method is its ability to handle the problem of reaction-phase equilibrium formally identical to the case of physical equilibrium. The problem is solved as the simultaneous solution of Eq. (1) and Eq. (2):

$$
\begin{aligned}
& \min G(n)=\sum_{\beta=1}^{N P} \sum_{i=1}^{N C} n_{i}^{\beta} \mu_{i}^{\beta} \\
& \sum_{\beta=1}^{N P} \sum_{i=1}^{N C} A_{j, i} n_{i}^{\beta}-b_{j}=0
\end{aligned}
$$

Where $n_{i}$ is the molar amount of component $i, \mu_{i}$ is the chemical potential of component $i, N P$ is number of phases, $N C$ is the number of components, $\beta$ is the phase of concerning system, and $A_{j, i}$ is the number of times the reaction invariant element $j$ has appeared in molecule $i$.

The key elements are noted as the binary elements (light key element (LK) and heavy key element (HK)). One can assign any pair of elements (or compounds) as LK and HK, with the lower boiling compound in the pair being the LK and the heavier boiling compound in the pair being the HK. For all other non-key compounds, those that have lower boiling points are therefore lighter than the light key and go with the LK, while those that have higher boiling points are heavier than the HK and go with the HK compound. This representation is similar in concept to the method of distillation design for a non-reactive multicomponent system proposed by (Hengstebeck, 1961). Note that LK and HK are selected according to the rules of key element selection given by Jantharasuk et al. (2011). It is well-known that the sum of mole fractions is always equal to 1 . Therefore, it is also the case when the mole fractions are given in terms of elements. Thus, the sum of mole fractions in a multi-element system is as follows:

$W_{L K}^{\beta}+W_{H K}^{\beta}+W_{L N K}^{\beta}+W_{H N K}^{\beta}=1$

Having the above summation, now one can represent the multi-element system in a new composition domain termed as "equivalent binary element composition" as follows (Jantharasuk et al., 2011):

$W_{e q}^{\beta}=W_{L K}^{\beta}+W_{H K}^{\beta}=1-\sum\left(W_{L N K}^{\beta}+W_{H N K}^{\beta}\right)$

where, the light key equivalent element composition is given as follows:

$W_{L K, e q}^{\beta}=\frac{W_{L K}^{\beta}}{W_{L K}^{\beta}+W_{H K}^{\beta}}$

and the element composition is given as below (Pérez-Cisneros et al., 1997):

$W_{j}^{\beta}=\frac{\sum_{i=1}^{N C} A_{j, i} x_{i}^{\beta}}{\sum_{i=1}^{N C} \sum_{j=1}^{M} A_{j, i} x_{i}^{\beta}}$ 
Many separation processes that involve heat and/or mass transfer involve a driving force. This driving force is usually defined as a difference in chemical and/or physical properties which the separation is based on (Gani and Bek-Pedersen, 2000; Wankat, 2012). The application of the driving force concept for distillation processes, reactive or not, (Bek-Pedersen and Gani, 2004) permits the determination of important distillation column design variables in terms of two parameters, the location and the size of the maximum driving force, $D_{x}$ and $D_{y}$, respectively. The feed stage location $\left(N_{F}\right)$ and the minimum reflux ratio, $\mathrm{RR}$ (and/or the boilup ratio, $\mathrm{RB}$ ) are determined from these two parameters for a given feed and product specification. It has been shown that operating at the maximum driving force results in an optimum reactive or non-reactive distillation column with minimum reboiler duty (Babi et al., 2014; BekPedersen and Gani, 2004; Gani and Bek-Pedersen, 2000; Jantharasuk et al., 2011; Sánchez-Daza et al., 2003) and better controllability (Alvarado-Morales et al., 2010; Hamid et al., 2010; Mansouri et al., 2015).

The two simple distillation design methods, the McCabe-Thiele (McCabe and Thiele, 1925) method and driving force approach (Bek-Pedersen and Gani, 2004), were extended to design of RDC columns. This is based on the element mass balance concept (Sánchez-Daza et al., 2003) where the reactive systems containing binary elements are exploited. Jantharasuk et al., (2011) extended the application domain of the reactive driving force approach and McCabe-Thiele method (Sánchez-Daza et al., 2003) to equivalent binary element compositions (more than two elements). It is defined as the difference in equivalent binary element composition between co-existing liquid and vapor phases which are at equilibrium or not (in this work equilibrium is assumed to have been achieved). Note that the binary equivalent based reactive driving-force diagram fully considers the extent of reaction on an equivalent element basis, and it is applied in the design of multi-element reactive distillation columns. The driving force based on binary equivalent elements is defined as (Jantharasuk et al., 2011):

$D F_{L K, e q}=W_{L K, e q}^{v}-W_{L K, e q}^{l}=\frac{W_{L K, e q}^{l} \alpha_{L K, e q}}{1+W_{L K, e q}^{l}\left(\alpha_{L K, e q}-1\right)}-W_{L K, e q}^{l}$

Where,

$\alpha_{L K, e q}=\frac{W_{L K, e q}^{v} / W_{L K, e q}^{l}}{W_{H K, e q}^{v} / W_{H K, e q}^{l}}=\frac{K_{L K}}{K_{H K}}$

Figure 1 depicts a generic driving force diagram with the location $\left(\mathrm{D}_{x}\right)$ and size of the maximum driving force $\left(\mathrm{D}_{y}\right)$. The feed stage location $\left(\mathrm{N}_{F}\right)$ and the minimum reflux ratio, $\mathrm{RR}$ (and/or the reboil ratio, $\mathrm{RB}$ ) are determined from these two parameters for a given feed and product specification. Points A and B correspond to the product specifications in the distillate and bottom of the reactive distillation column in terms of light key equivalent element composition. 


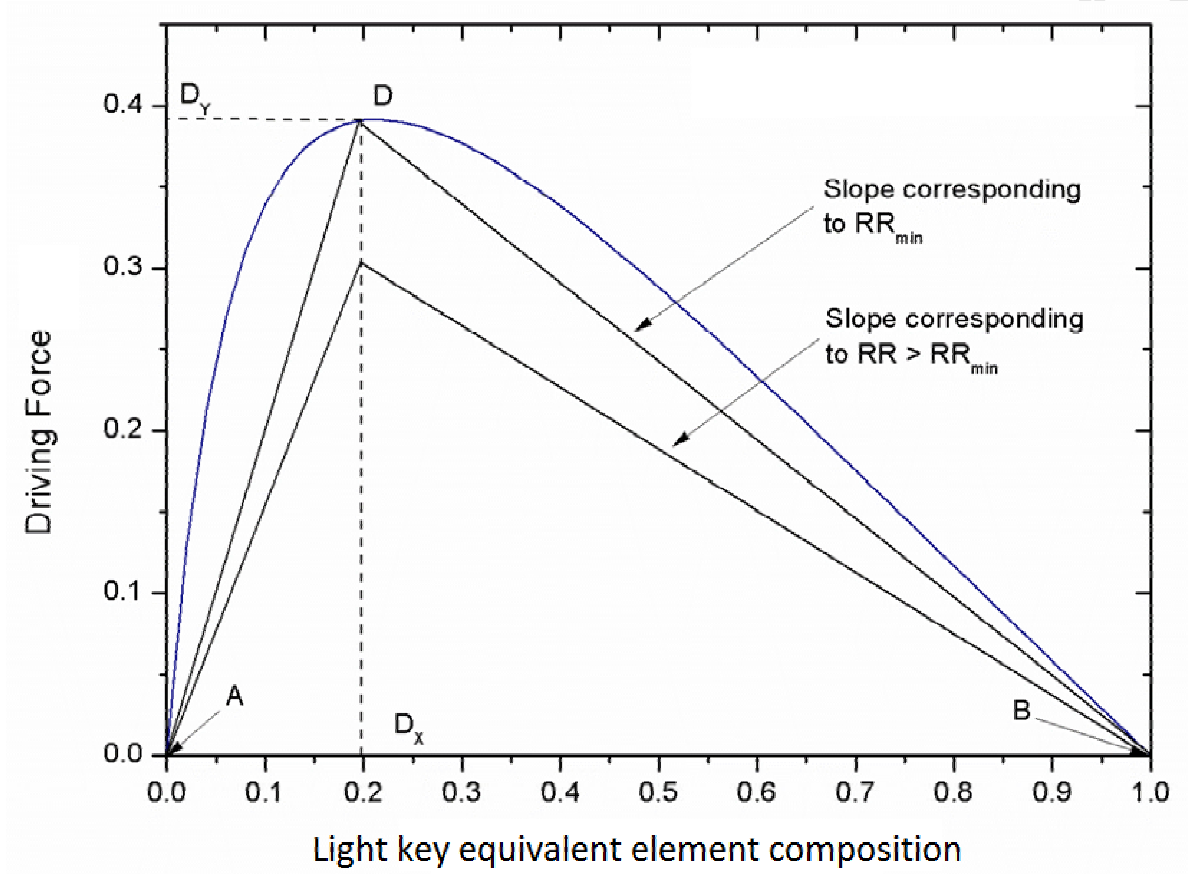

Figure 1: A generic driving force diagram for equivalent binary element system.

\section{3}

8

\section{Integrated process design and control framework}

In this work, it is assumed that the process flowsheet is fixed (i.e. reactive distillation column) as well as the design targets, feed specifications and process conditions. Therefore, the objective is to find the design variables, the operating conditions (including set-points for controlled variables) and controller structure that optimize the plant economics and, simultaneously, a measure of the plant controllability, subject to a set of constraints, which ensure appropriate dynamic behavior and process specifications. The integrated process design and control problem is formulated as a generic optimization problem in which a performance objective function in terms of design, control and cost is optimized subject to a set of constraints: process (dynamic and steady state), constitutive (thermodynamic states) and conditional (process-control specifications) models-equations. The general formulation of the problem is (Sendin et al., 2004): 


$$
\min _{x} F(\dot{x}, x, p, h)=\left[\begin{array}{l}
F_{1}(\dot{x}, x, u, y, \theta, h) \\
F_{2}(\dot{x}, x, u, y, \theta, h)
\end{array}\right]
$$

Subject to:

$$
\begin{aligned}
& f(\dot{x}, x, u, y, \theta, d, h)=0 \\
& x\left(t_{0}\right)=x_{0} \\
& k(x, u, y, \theta, h)=0 \\
& g(x, u, y, \theta, h) \leq 0 \\
& h^{L} \leq h \leq h^{U}
\end{aligned}
$$

1 Here $h$ is the vector of decision variables, $x$ is the vector of dynamic state variables, $F$ is the vector of 2 objective functions ( $F_{1}$ is a combination of capital and/or operation costs or energy, and $F_{2}$ is the 3 controllability measure), $f$ is the set of differential and algebraic equality constraints describing the system 4 dynamics (mass, energy and momentum balances, i.e. the non-linear process model), and $k$ and $g$ are possible equality and inequality path and/or point constraints which express additional requirements for 6 the process performance. However, solving Eq. (7)-(12) simultaneously using a dynamic optimization 7 approach can be difficult if the process model consisting of balance, constitutive and process control

8 equations is large and non-linear.

9 The feasible solutions to integrated process design and control problem may be located in a relatively 10 small region of the search space. This is due to the large number of constraints involved. Therefore, the capability of solving such a problem largely falls into the effectiveness of the solution strategy and locating the feasible solutions (one of these solutions is the optimal solution). Thus, one approach as an alternative to solve a dynamic optimization and in order to manage the complexity is using a decomposition-based solution strategy. In this approach, the problem is decomposed into a set of subproblems that are solved according to pre-defined calculation order. In this way, after every sequential sub-problem, the search space for feasible solutions is reduced and a sub-set of design-manipulated and/or decision variables are fixed. When all the constraints are satisfied, it remains to calculate the objective function for all the identified feasible solutions to locate the optimal solution. This leads to a problem that is significantly smaller and can be solved more easily. Therefore, while the sub-problem complexity may or may not increase with every subsequent stage, the number of feasible solutions is reduced after each stage. Figure 2 shows a schematic diagram of how the integrated process design and control can be tackled using a decomposition-based solution strategy. 


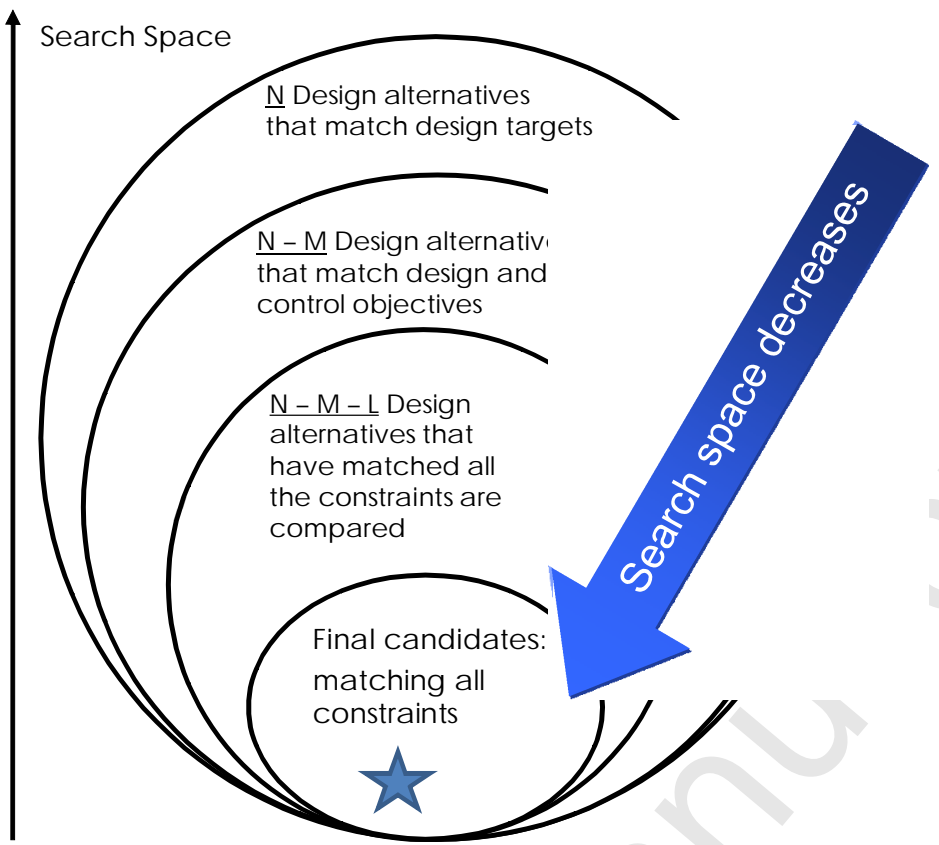

Figure 2: The number of solutions is reduced after each sub-problem.

From a process design point of view, for specified inputs, $u$, and disturbances, $d$, values for states, $x$, and outputs, $y$, that satisfy a set of design specifications (process design objectives) are determined at the maximum driving force. In this case $x$ and $y$ also define some of the operational conditions for the process. From a controller design point of view, for any changes in $d$ and/or set point values in $y$, values of $u$ that restores the process to its optimal designed condition are determined. It should be noted that the solution for $x$ and $y$ is directly influenced by $\theta$ (the constitutive variables such as reaction rate or equilibrium constant). Note that solution of the balance equations for $x$ and $y$ is influenced by $\theta$ (the constitutive variables such as equilibrium constant or reaction rate). Also, since $x$ and $y$ are intensive variables, they may be used to formulate problems related to synthesis, design and control. The analysis of the model equations, therefore, orders the variables in terms of $x, y, u, d$ and $\theta$ for integrated design and control problems. For process design, $\theta$ indirectly determines the feasibility of the process which in this case it is intended to be at the maximum driving force. Therefore, the value of $\theta$ determines the feasible design for control. Therefore, $\mathrm{d} \theta / \mathrm{d} x$ indirectly influences the process operation and controller structure selection and/or design.

The decomposition-based framework proposed in this work consists of five steps: (1) the problem is formulated and the objective function is defined, (2) the number of elements representing the reaction mixture is determined, (3) key light and heavy key elements are identified (4) the reactive distillation column is designed based on key elements using driving force approach, and in the last step (5) dynamic verification of the design is performed. The decomposition-based framework proposed in this work for integrated design and control of reactive distillation processes is illustrated in Figure 3. Note that the process design and control objectives are tied together at the maximum driving force. These objectives are evaluated and calculated as the multi-objective performance function. Therefore, if a maximum of the driving force is identified, the design-control goals will always be satisfied. If the system does not have a 
maximum of the driving force, then the proposed algorithm cannot be applied. The simulations in steps 4 2 and 5 are carried out to get the quantitative values but the concept of integration guarantees achievement 3 of the design-control goals (as confirmed by the numerical and analytical results).

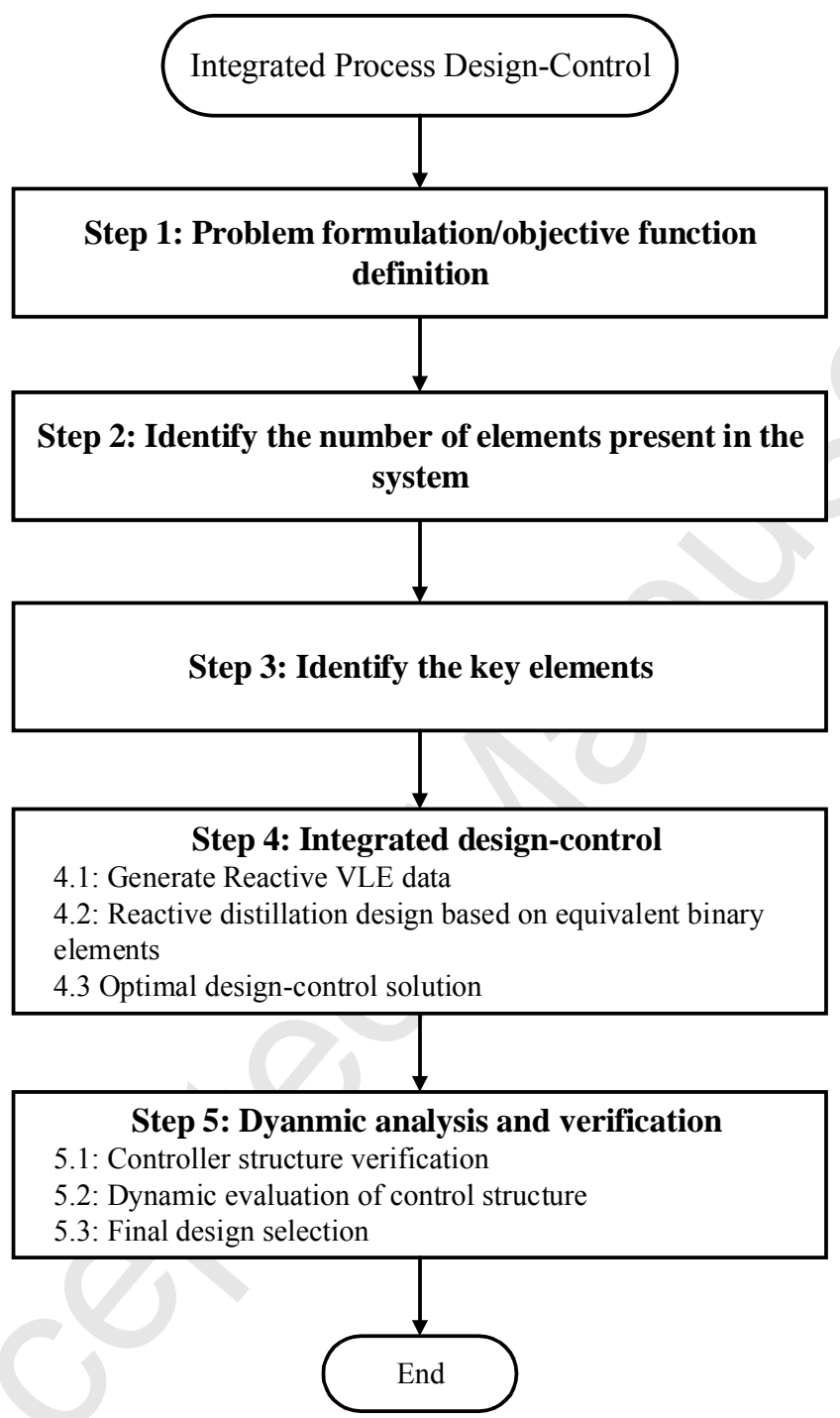

5 Figure 3: Framework of the integrated process design and control of multi-element reactive distillation processes.

\subsection{Step 1: Problem formulation and objective function definition}

The process specifications including the information on raw material and products, reaction data, 8 catalysts, feed temperature, pressure and composition, product composition and design targets are 9 collected in this step. The performance objective function which is going to be maximized or minimized is also defined in this step. This includes steady-state economic and/or energy metrics as well as controller performance metrics. 
2 The number of elements present in the system is calculated from Eq. (13)

$N E=N C-N R$

3 Where $N C$ is the number of compounds and $N R$ is the number of reactions. The formula matrix is written

4 with the constituent elements $(\mathrm{j}=1,2, \ldots, N E)$ as rows and the species $(\mathrm{i}=1,2, \ldots, \mathrm{NC})$ as columns.

\section{$54.3 \quad$ Step 3: Identify the key elements}

6 The equivalent binary elements, that is light key and heavy key elements, are selected according to the

7 rules of key element selection (Jantharasuk et al., 2011) and they are as follows:

8 Rule (i): The mixture on component basis is arbitrarily considered as attaining the expected reaction 9 conversion. The corresponding compositions are later applied with the 'Rule of key element selection' in the next steps.

11 Rule (ii): The element that is contained by the remaining lightest component should not be specified as heavy key and/or heavy non-key element.

13 Rule (iii): The element that is contained by the remaining heaviest component should not be specified as 14 light key and/or light non-key element.

Rule (iv): The key element should be presented along the whole column (should be contained in both distillate and bottom products).

\subsection{Step 4: Integrated design-control}

The objective of this step is to find the design-control option for the reactive distillation column using the driving force approach. Therefore, the search space within the design targets identified in Stage 1 is further reduced in this stage. The objective is to validate the targets defined in Stage 1 by finding acceptable values of controlled and manipulated variables together with their set-points and pairing.

\subsubsection{Step 4.1: Generate vapor-liquid equilibrium data}

The vapor-liquid equilibrium (VLE) data is either obtained from experiments or computation of reactive bubble points or dew points. In this work, the reactive bubble point data are calculated using the algorithm proposed by Sánchez-Daza (2003). Figure 4 presents the algorithm to generate equivalent binary element reactive phase diagram (Algorithm 1). Note that in this algorithm, the choice of discretization may affect the accuracy of the results. Therefore, it is recommended that a discretization interval of at least 0.05 is used to perform the calculations. Furthermore, it should be noted that with the element mole fractions there is not any chance for obtaining negative values for composition variables.

30 Note that activity coefficient models can be also used for fugacity balances. 


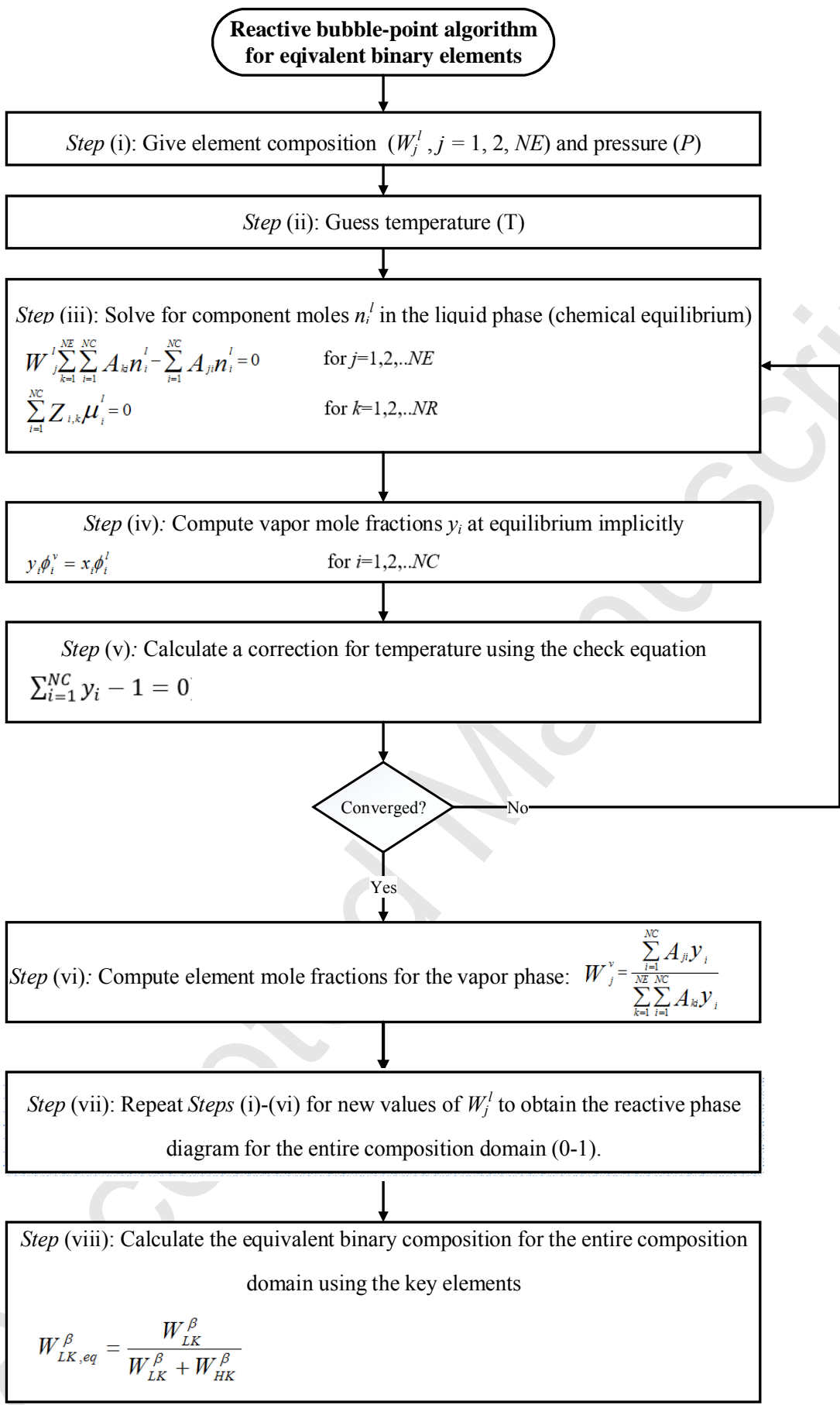

Figure 4: Algorithm 1, for constructing reactive phase diagram based on equivalent binary elements

\section{$3 \quad 4.4 .2$ Step 4.2: Reactive distillation design based on equivalent binary elements}

4 The objective of this step is to find the reactive distillation column design based on equivalent binary 5 element at the maximum driving force (i.e. number of stages, reflux ratio and feed location). The steps 6 required to perform this task are given in the algorithm presented in Figure 5 (Algorithm 2). After 
1 application of Algorithm 2, perform steady-state simulation of the process to verify that the design 2 objectives are satisfied.

3

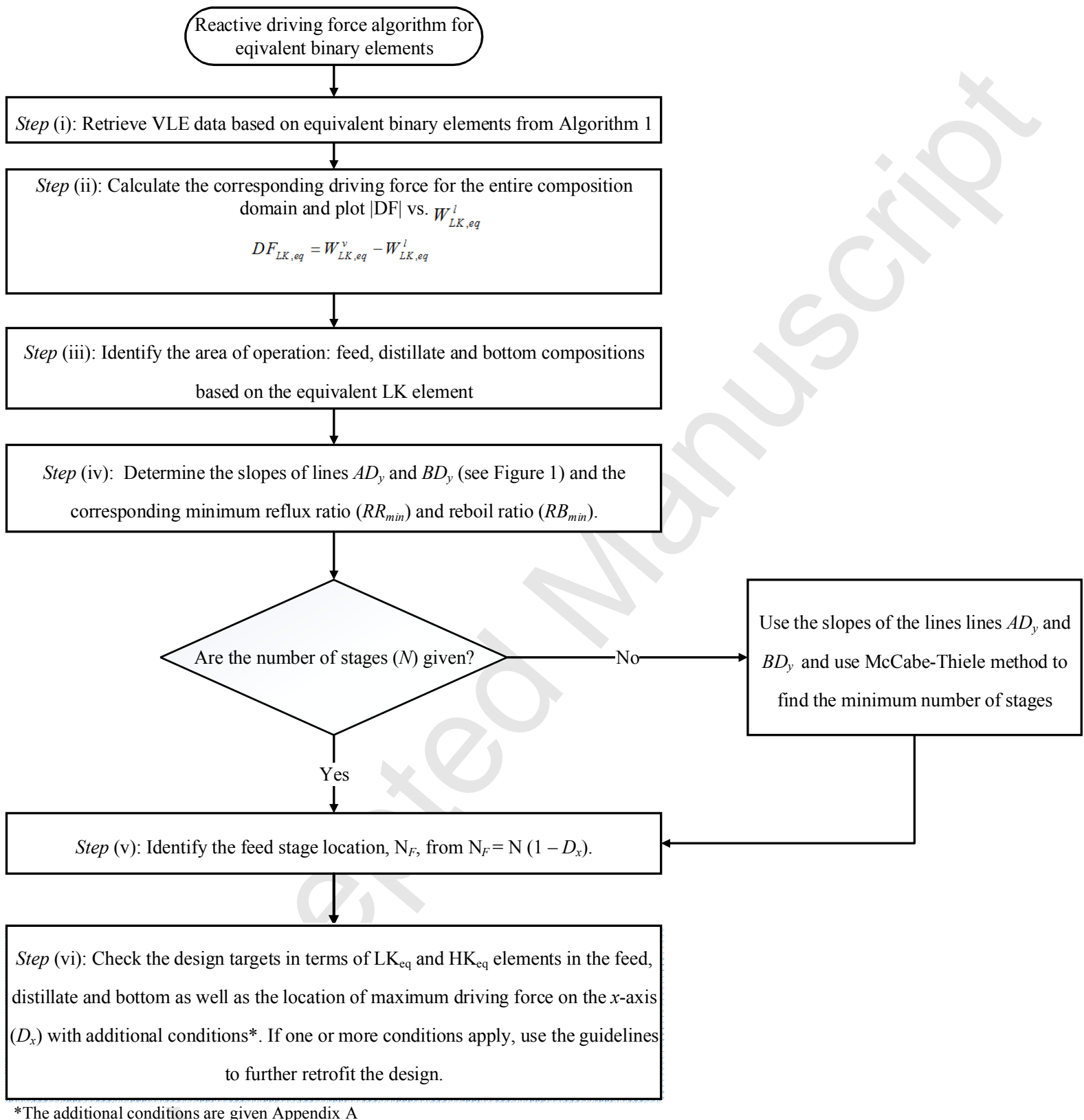

Figure 5: Algorithm 2, for reactive distillation column design based equivalent binary elements using driving force approach 
In this step, the controller structure is selected with respect to two main criteria which are highlighted below:

i. Sensitivity of $(\mathrm{d} y / \mathrm{d} d)$ : If the sensitivity of controlled variables, $y$, with respect to disturbances in the feed, $d$, is low it means that the process is less sensitive to disturbances and therefore, it is more robust in maintaining the controlled variables at their set-point in the presence of disturbances.

ii. Sensitivity of $(\mathrm{d} u / \mathrm{d} y)$ : If the sensitivity of manipulated variables to controlled variables is high it will determine the best controller pairing and consequently controller action.

Therefore, the above key criteria are verified at the maximum driving force analytically using Algorithm 3. Note that we have previously shown the detailed mathematical derivations for binary elements for this algorithm (Mansouri et al., 2016a, 2015). The only difference here is that the derivations are based on equivalent binary elements instead of binary elements. Interested reader can refer to the above mentioned paper to obtain detailed analytical derivations and here, only the final equations are given.

\section{Algorithm 3: Optimal design-control structure determination}

Step (i): Selection of controlled variables

The primary controlled variable is the $x$-axis value on the driving force diagram which is $\mathrm{W}_{L K, \text { eq }}^{l}$ (see Fig. 1). This resembles the element composition of the light key equivalent element. The secondary controlled variables are the product composition (design targets), which are measurable variables and they are at the top and bottom of the column, $\mathrm{W}_{L K, e q}^{d}$ and $\mathrm{W}^{B}{ }_{L K, e q}$ (based on equivalent elements). The reason behind this selection is that conceptual variables (that is driving force, DF) cannot be measured directly.

Step (ii): Sensitivity of controlled variables to disturbances

In order to calculate the sensitivity, apply a chain rule to relate the derivatives of primary controlled variable to the derivatives of the secondary controlled variables. In order to apply the chain rule where the design variables vector is $y=\left[W_{L K, e q}{ }^{d} W_{L K, e q}{ }^{B}\right], x=W_{L K, e q}^{l}$ and $\theta=D F_{L K, e q}$ is selected on the $y$-axis of the driving force diagram. The disturbance vector is, $d=\left[\begin{array}{ll}\mathrm{F}_{f} & \mathrm{Z}_{W f}\end{array}\right]$ (feed flowrate and feed composition of light equivalent element). Therefore, the chain rule is expressed as in Eq. (14): 


$$
\begin{aligned}
& \frac{d y}{d d}=\left[\begin{array}{cc}
\frac{d W_{L K, e q}^{d}}{d F_{f}} & \frac{d W_{L K, e q}^{d}}{d z_{W_{f}}} \\
\frac{d W_{L K, e q}^{B}}{d F_{f}} & \frac{d W_{L K, e q}^{B}}{d z_{W_{f}}}
\end{array}\right]= \\
& {\left[\left(\frac{d W_{L K, e q}^{d}}{d D F_{L K, e q}}\right)\left(\frac{d D F_{L K, e q}}{d W_{L K, e q}^{l}}\right)\left(\frac{d W_{L K, e q}^{l}}{d F_{f}}\right)\left(\frac{d W_{L K, e q}^{d}}{d D F_{L K, e q}}\right)\left(\frac{d D F_{L K, e q}}{d W_{L K, e q}^{l}}\right)\left(\frac{d W_{L K, e q}^{l}}{d z_{W_{f}}}\right)\right]} \\
& {\left[\left(\frac{d W_{L K, e q}^{B}}{d D F_{L K, e q}}\right)\left(\frac{d D F_{L K, e q}}{d W_{L K, e q}^{l}}\right)\left(\frac{d W_{L K, e q}^{l}}{d F_{f}}\right)\left(\frac{d W_{A}^{B}}{d D F_{L K, e q}}\right)\left(\frac{d D F_{L K, e q}}{d W_{L K, e q}^{l}}\right)\left(\frac{d W_{L K, e q}^{l}}{d z_{W_{f}}}\right)\right]}
\end{aligned}
$$

Since the driving force diagram is always concave, therefore, the value of $d D F_{L K, e q} / d W_{L K, e q}^{l}=0$ at the maximum driving force. Therefore, the least sensitivity of controlled variables to disturbances is achieved at the maximum driving force and (15) is obtained as follows:

$$
\frac{d y}{d d}=\left[\begin{array}{cc}
\frac{d W_{L K, e q}^{d}}{d F_{f}} & \frac{d W_{L, e q}^{d}}{d z_{W_{f}}} \\
\frac{d W_{L K, e q}^{B}}{d F_{f}} & \frac{d W_{L K, e q}^{B}}{d z_{W_{f}}}
\end{array}\right] \approx\left[\begin{array}{ll}
0 & 0 \\
0 & 0
\end{array}\right]
$$

\section{Step (iii): Selection of the controller structure}

The potential manipulated variables are, $u=[\mathrm{L} \mathrm{V}]$, which are represented by reflux ratio (RR) and boilup ratio (RB). Hence, the sensitivity of the secondary controlled variables to the manipulated variables is calculated after some mathematical derivation similar to those by Mansouri et al. (2015). Thus, (16) presents the sensitivity of controlled variables, $y$, to manipulated variables, $u$, as follows:

$$
\begin{gathered}
\frac{d y}{d u}=\left[\begin{array}{cc}
\frac{d W_{L K, e q}^{d}}{d R R} & \frac{d W_{L K, e q}^{d}}{d R B} \\
\frac{d W_{L K, e q}^{B}}{d R R} & \frac{d W_{L K, e q}^{B}}{d R B}
\end{array}\right]= \\
{\left[\begin{array}{cc}
D F_{L K, e q}+(R R+1)\left(\frac{d D F_{L K, e q}}{d W_{L K, e q}^{l}}\right)\left(\frac{d W_{L K, e q}^{l}}{d R R}\right)+\frac{d W_{L K, e q}^{l}}{d R R} & (R R+1)\left(\frac{d D F_{L K, e q}}{d W_{L K, e q}^{l}}\right)\left(\frac{d W_{L K, e q}^{l}}{d R B}\right)+\frac{d W_{L K, e q}^{l}}{d R B} \\
\frac{d W_{L K, e q}^{l}}{d R R}-\left(\frac{d D F_{L K, e q}}{d W_{L K, e q}^{l}}\right)\left(\frac{d W_{L K, e q}^{l}}{d R R}\right) R B & \frac{d W_{L K, e q}^{l}}{d R B}-D F_{L K, e q}
\end{array}\right]}
\end{gathered}
$$

Assuming that $d W_{A}^{l} / d R R=d W_{A}^{l} / d R B=0,(17)$ is obtained (this corresponds to a system with no or little cross interactions between $y$ and $u$ since changes in $u$ cannot propagate through column). The best controller structure is easily determined by looking at the value of $\mathrm{d} y / \mathrm{d} u$. It is noted from (17) that since the values of $d W_{A}^{d} / d R R$ and $d W_{A}^{B} / d R B$ are bigger, controlling $W_{L K, e q}{ }^{d}$ by manipulating $R R$ and controlling $W_{L K, e q}^{B}$ by manipulating $R B$ will require less control action. Therefore, for the optimal design obtained at the maximum driving force, the control structure is always given by equation (17) and it is verified by analytical analysis that it is the optimal-design control structure. 


$$
\frac{d y}{d u}=\left[\begin{array}{ll}
\frac{d W_{L K, e q}^{d}}{d R R} & \frac{d W_{L K, e q}^{d}}{d R B} \\
\frac{d W_{L K, e q}^{B}}{d R R} & \frac{d W_{L K, e q}^{B}}{d R B}
\end{array}\right]=\left[\begin{array}{cc}
D F_{L K, e q} & 0 \\
0 & -D F_{L K, e q}
\end{array}\right]
$$

\section{Algorithm 4: Control structure verification}

Step (i): Obtain the linear representation of the optimal design control option at the maximum driving force; either by using the transfer functions from step test between each manipulated $(u)$ and control variable $(y)$ or linearizing the model and obtaining state-space matrices (A; B;C; D).

Step (ii): Construct the steady-state gain matrix $(G)$ from the transfer functions.

Step (iii): Verify that the gain matrix $G$ has non-zero determinant.

Step (iv): Calculate the relative gain matrix (RGA) using Eq. (18) as follows (Bristol, 1966):

$$
R G A(G)=G \otimes\left(G^{-1}\right)^{T}
$$

Step (v): Verify that pairings such that the rearranged system, with the selected pairings along the diagonal, has an RGA matrix element close to unity, and off-diagonal elements close to zero (for a $2 \times 2$ system); therefore, control structure at the maximum driving force has least interactions with each other for the pairing given by Eq. (17).

Step (vi): Calculate Niederlinski Index using Eq. (19) as follows (Chiu and Arkun, 1991; Corriou, 2004):

$$
N_{I}=\frac{\operatorname{det}|G|}{\prod_{i} G_{i i}}
$$

If this index is negative the system is unstable whatever the tuning of the controllers are. Else,

If it is positive, it is impossible to conclude. Thus, it is a sufficient condition, except for multivariable systems of size lower than or equal to 2 , where it is also necessary.

4.5.2 Step 5.2: Dynamic evaluation of control structure

The objective of this step is evaluate the close-loop performance of the control structure identified and verified in Step 4 and Step 5.1, respectively; in the presence of disturbances in the feed. Therefore, to this end Algorithm 5 is applied. 


\section{Algorithm 5: Control structure evaluation}

Step (i): Select a disturbance scenario in the feed.

Step (ii): Perform open-loop simulation in the presence of the disturbance to observe to what extent the control variables deviate from the set-point. If the deviation is less than $2 \%$ return to Step (i) and select another disturbance scenario.

Step (iii): Select an appropriate control algorithm at regulatory level.

Step (iv): Retrieve nominal steady-state values for the control variables from Step 4.2.

Step (v): Select an appropriate tuning method (IMC rules (Rivera et al., 1986) or SIMC rules (Skogestad, 2003)) to obtain tuned controller parameters.

Step (vi): Perform closed-loop simulation and verify that the disturbance is rejected and the system is recovered to its original set-points.

2 In this step the value of each term of the performance objective function is calculated.

\section{Application example}

In order to demonstrate the application of the framework for integrated process design and controller design of multi-element systems, the synthesis of methyl-tert-butyl-ether (MTBE) and its well-known production via reactive distillation is selected (Grosser et al., 1987; Schrans et al., 1996; Sharma and Singh, 2010). Furthermore, it is assumed in this case (since chemical reaction takes fast) that the 8 equilibrium is achieved.

\subsection{Step 1: Problem formulation and objective function definition}

For the case of MTBE synthesis the advantages of using a reactive distillation are very well established. The reaction of methanol and isobutene yields MTBE. However, normally pure isobutene is not fed to the process and it also contains some 1-butene as impurity (inert). The MTBE reaction is exothermic and reversible and it takes place in presence of an acidic catalyst (Al-Jarallah et al., 1988). The reaction is therefore expressed as follows:

$$
\text { isobutene }\left(\mathrm{C}_{4} \mathrm{H}_{8}\right)+\text { methanol }\left(\mathrm{CH}_{4} \mathrm{O}\right)+1-\text { butene }\left(\mathrm{C}_{4} \mathrm{H}_{8}\right) \leftrightarrow \operatorname{MTBE}\left(\mathrm{C}_{5} \mathrm{H}_{12} \mathrm{O}\right)+1-\text { butene }\left(\mathrm{C}_{4} \mathrm{H}_{8}\right)
$$

The design feed compositions and product specifications are obtained (Pérez-Cisneros, 1997) and summarized in Table 1. Note however, the main target to be satisfied is the MTBE bottom composition.

Table 1: Design targets and product specifications (Pérez-Cisneros, 1997)

\begin{tabular}{lllll}
\hline Component & Structure & Feed & Distillate & Bottom \\
\hline$i$-butene & $\mathrm{C}_{4} \mathrm{H}_{8}$ & 0.590 & 0.773 & 0.061 \\
Methanol & $\mathrm{CH}_{4} \mathrm{O}$ & 0.343 & 0.000 & 0.012 \\
1-butene & $\mathrm{C}_{4} \mathrm{H}_{8}$ & 0.067 & 0.196 & 0.024 \\
MTBE & $\mathrm{C}_{5} \mathrm{H}_{12} \mathrm{O}$ & 0 & 0.031 & 0.907 \\
\hline
\end{tabular}

Feed flowrate: $100 \mathrm{kmol} / \mathrm{h}$; Feed temperature and pressure: $320 \mathrm{~K}$ and $11 \mathrm{~atm}$

18 The design-control multi-objective performance function is defined as below: 


$$
f_{\text {Obj }}=\min \left(J_{1}, J_{2}, J_{3}, J_{4}, J_{5}\right)
$$

$J_{2}=I A E=\int_{0}^{\infty}\left|y-y_{s p}\right| d t$

$J_{3}=T V=\sum_{i=1}^{\infty}\left|u_{i+1}-u_{i}\right|$

$J_{4}$ and $J_{5}$ are set of metrics to evaluate the appropriateness of the control structure and they are RGA which for the design at the maximum driving force should propose the structure with the least interactions between the loops, and $N_{I}$ which is a measure of system stability, respectively.

\subsection{Step 2: Identify the number of elements present in the system}

The number of elements present in the system is identified by applying Eq. (13). In this case there are four compounds and one reaction. Therefore, the reaction mixture is represented by three elements and the formula matrix is given in Table 2 .

Table 2: Elements representing the system and formula matrix

\begin{tabular}{|c|c|c|c|c|}
\hline \multicolumn{5}{|c|}{$\begin{array}{c}\text { Isobutene }\left(\mathrm{C}_{4} \mathrm{H}_{8}\right)+\text { Methanol }\left(\mathrm{CH}_{3} \mathrm{OH}\right)+1-\mathrm{Butene} \leftrightarrow \mathrm{MTBE}\left(\mathrm{C}_{5} \mathrm{H}_{12} \mathrm{O}\right)+1-\mathrm{Bu} \\
\left.\text { Element definition: } \quad A=\mathrm{C}_{4} \mathrm{H}_{8} \quad B=\mathrm{CH}_{3} \mathrm{OH} C=\mathrm{C}_{4} \mathrm{H}_{8} \text { (isomer }\right) \\
\text { Element reaction: } A+B+C \leftrightarrow A B+C\end{array}$} \\
\hline \multicolumn{5}{|c|}{\begin{tabular}{|l} 
Formula Matrix \\
\end{tabular}} \\
\hline & Isobutene & Methanol & MTBE & 1-Butene \\
\hline$A$ & 1 & 0 & 1 & 0 \\
\hline$B$ & 0 & 1 & 1 & 0 \\
\hline C & 0 & 0 & 0 & 1 \\
\hline
\end{tabular}

\subsection{Step 3: Identify the key elements}

Following the rules given in Step 3 of the framework (see section 4.3), the light key and heavy key elements are identified as B and A to be light key (LK) and heavy key (HK) elements, respectively.

\subsection{Step 4: Reactive distillation column design}

\subsubsection{Step 4.1: Generate vapor-liquid equilibrium data}

In this step, Algorithm 1 is applied to generate the vapor-liquid equilibrium data. SRK equation of state has been used for vapor phase fugacity coefficients and Wilson model for liquid phase activity coefficients. The phase diagram for the MTBE multi-element system based on equivalent binary elements is presented in Figure 6. 


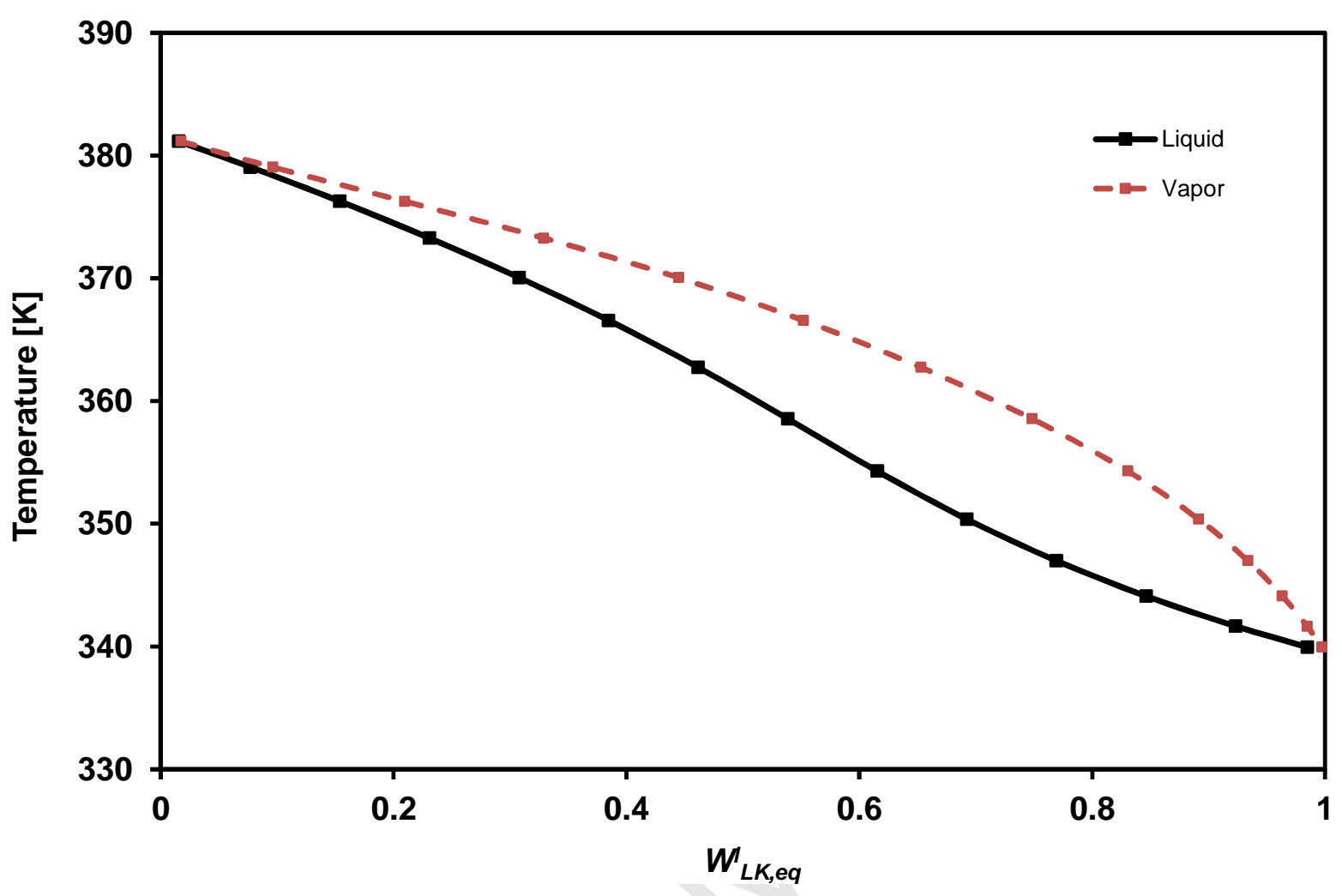

Figure 6: phase diagram for MTBE multi-element system at $11 \mathrm{~atm}$

\section{$3 \quad$ 5.4.2 Step 4.2: Reactive distillation design based on equivalent binary elements}

4 In this step, the reactive distillation column is designed at the maximum equivalent binary driving force 5 by applying Algorithm 2. The area of operation is identified on the $x$-axis of the driving force diagram 6 given in Figure 7. The slopes of the lines corresponding to minimum reflux and boilup ratios are 7 determined. Note however, in this case study since the number of stages is not given, these slopes are 8 used in a McCabe-Thiele method to find the minimum number of stages. The equivalent binary element 9 McCabe-Thiele diagram is given in Figure 8. The minimum number of stages are found to be five reactive stages plus non-reactive condenser and reboiler (from a practical point of view presence of reaction in reboiler and condenser has not been reported, therefore these two stages are added). The feed and product specifications are checked against additional conditions (see Appendix A) and the feed location is identified to be at stage 4 from the top of the column. 


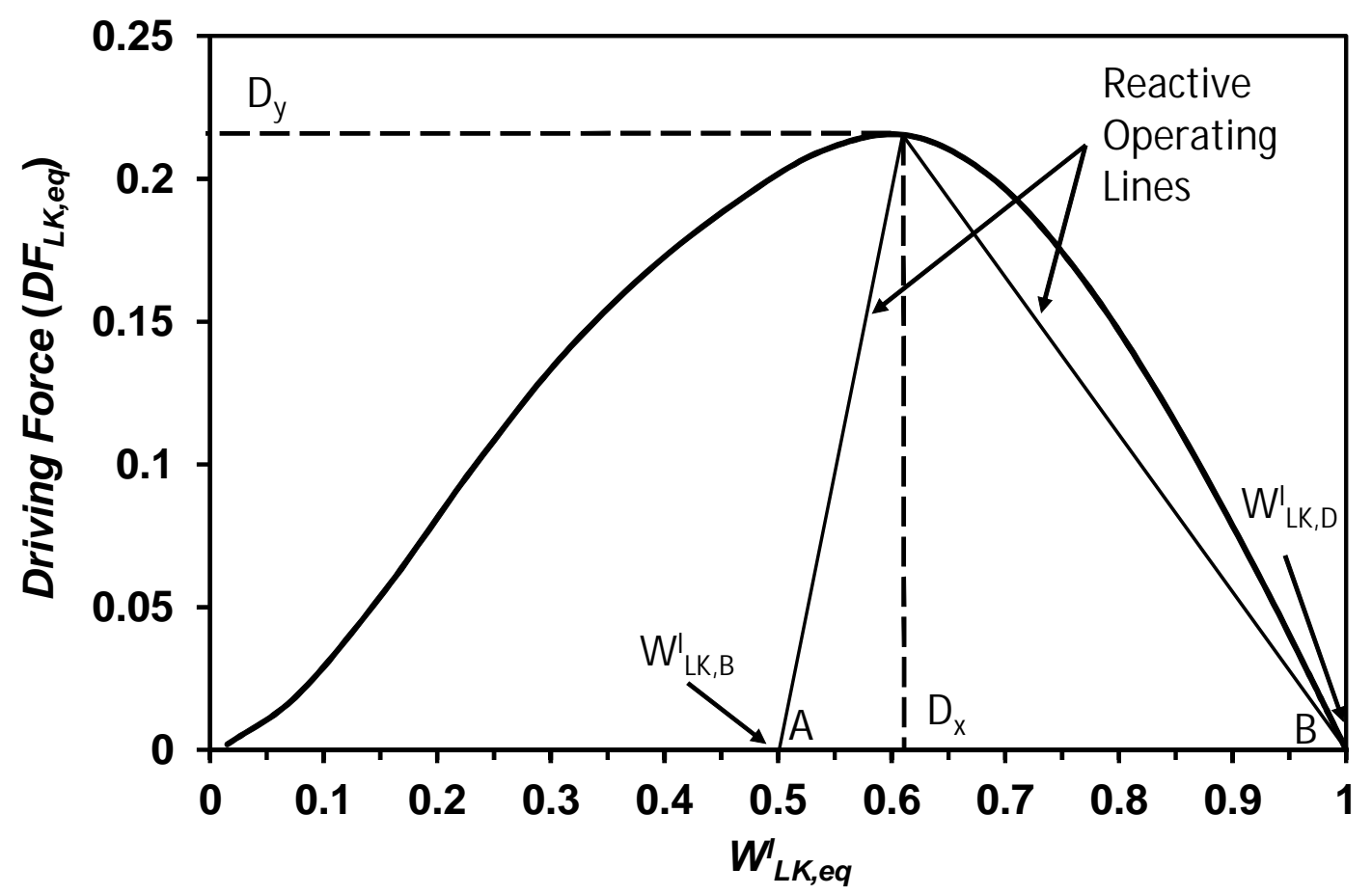

Figure 7: Reactive binary equivalent element driving force diagram for MTBE multi-element system

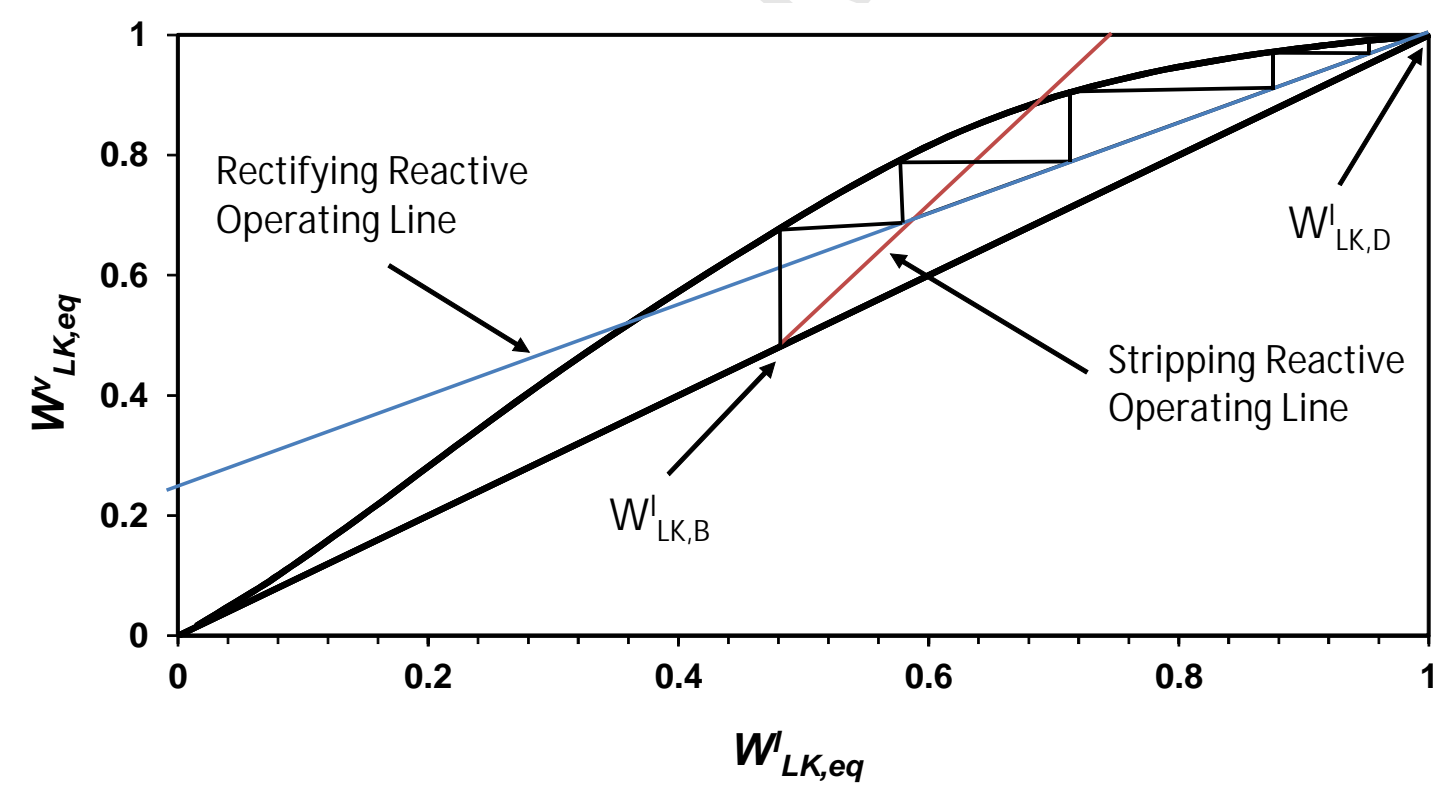

Figure 8: Reactive McCabe-Thiele diagram and calculations for MTBE multi-element system.

In order to verify that the design objectives in terms of product specifications are satisfied, rigorous steady-state simulation of the reactive distillation column at the maximum driving force is performed. Figure 9 shows the composition profile of the compounds present in the system across the column. 


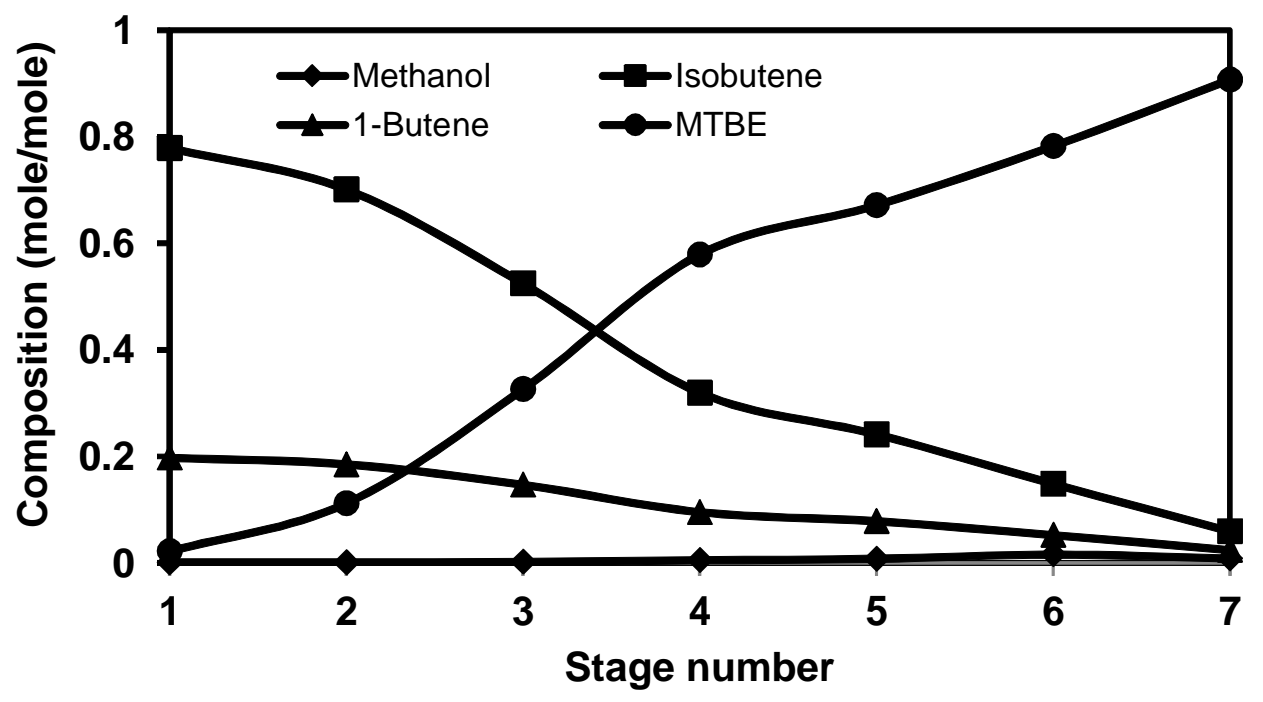

1

Figure 9: Composition profile across the reactive distillation column.

As it is shown in Figure 9, the design objectives set in Step 1 (see Table 1) are satisfied. It must be noted that the last step of the framework, which is dynamic validation, is to showcase that the design specifications are matched and system is sufficiently well restored to its original set-points in the presence of disturbances in the feed (load change is also a disturbance in the feed). Table 3, presents the reactive distillation column design parameters.

Table 3: Reactive distillation design parameters

\begin{tabular}{cccccc}
\hline Number of stages & Feed location & Reflux ratio & Boilup ratio & Reboiler duty (kW) & Condenser duty (kW) \\
\hline 7 & 4 & 2.83 & 1.27 & 323.3 & 533.3 \\
\hline
\end{tabular}

\subsubsection{Step 4.3: Optimal design-control solution}

The controlled variables and manipulated variables are determined according to Algorithm 3 since the reactive distillation column is designed at the maximum equivalent binary element driving force. They are top and bottom compositions for controlled variables and, reflux rate and reboiler duty for manipulated variables. Furthermore, the values of $d D F_{L K, e q} / \mathrm{d} W_{L K, e q}^{l}$ are calculated and plotted against $W_{L K, e q}^{l}$. As it is shown in Figure 10, at the maximum driving force there is the least sensitivity of the controlled variables to the disturbances, and, the highest sensitivity to the manipulated variables. The control structure is therefore determined by Eq. (17). Note that $d D F_{L K, e q} / \mathrm{d} W_{L K, e q}^{l}$ on the y-axis of Figure 10 corresponds to the slope of the line between each two points on the driving force diagram (see Figure 7) which in turn corresponds to the derivative value the driving force with respect to $W_{L K, e q}^{l}$. 


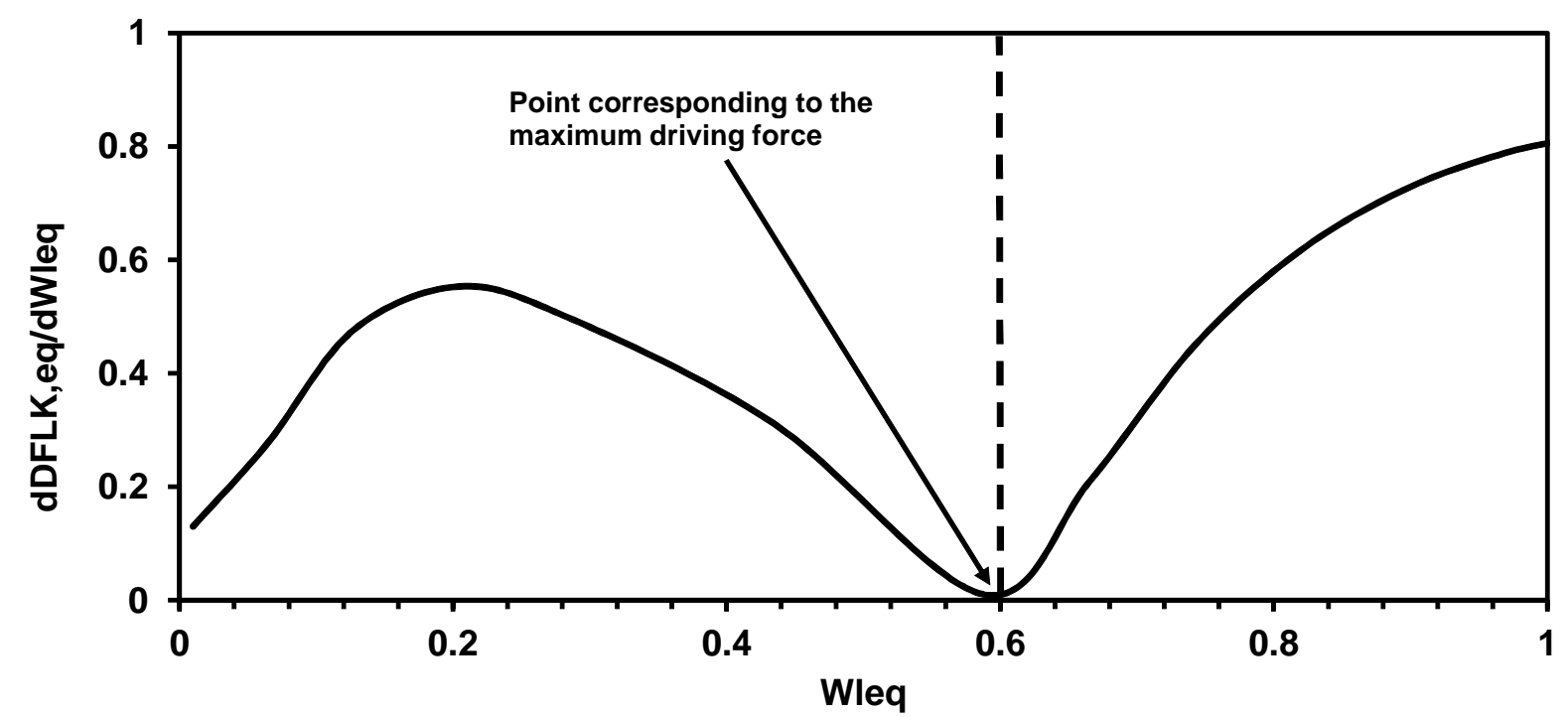

Figure 10: The values of $d D F_{L K, e q} / \mathrm{d} W_{L K, e q}^{l}$ are calculated and plotted against $W_{L K, e q}^{l}$

\subsection{Step 5: Dynamic analysis and verification}

\subsubsection{Step 5.1: Control structure verification}

In order to verify the control structure, Algorithm 4 is applied. The linearized model of the process, i.e. state-space model is obtained and the steady-state gain matrix was constructed for a $2 \times 2$ system. The gain matrix had non-zero determinant and the RGA is obtained as follows:

$$
R G A=\left[\begin{array}{cc}
1.03 & -0.96 \\
-0.96 & 1.03
\end{array}\right]
$$

Therefore, it can be verified that selected controller pairing for the design corresponding to the maximum driving force has the least interactions between the loops as the diagonal values (for a $2 \times 2$ system) are close to unity. Furthermore, the Niederlinski index $\left(N_{I}\right)$ is calculated and it is found to be $N_{I}=0.0372$ which is positive. This verifies that the system is not unstable.

\subsubsection{Step 5.2: Control structure evaluation}

In order to evaluate the performance of the control structure, Algorithm 5 is applied. To this end, first open-loop simulation is performed in presence of a disturbance scenario which is a $+16.5 \%$ step change in the methanol flowrate. The open-loop response of the system to this disturbance is shown in Figure 11. The controller structure is then implemented using Proportional-Integral (PI) type controllers on the reactive distillation according to Eq. (17). The controller tuning parameters are obtained using IMC rules. Furthermore, a perfect pressure control is assumed and the level controllers for reboiler and condenser are Proportional (P) type controllers. 

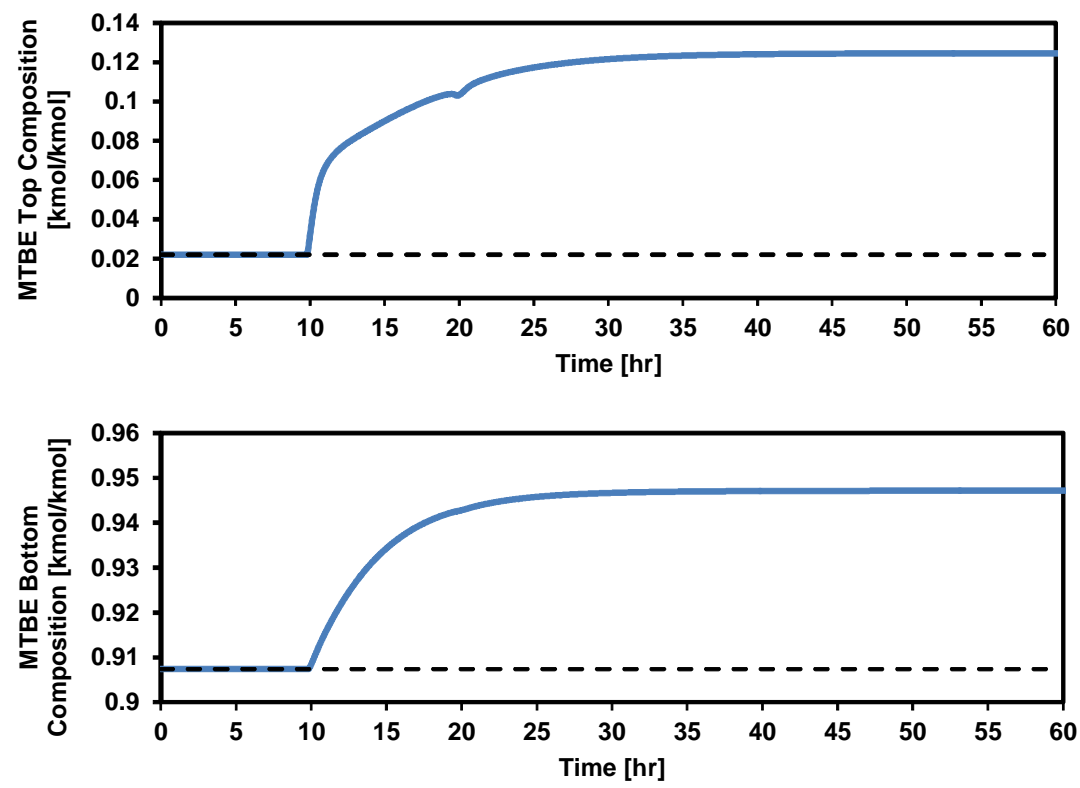

Figure 11: Open-loop response of the optimal design-control solution to a disturbance in the feed.

3 Figure 12, presents the closed-loop performance of the reactive distillation column design to $+16.5 \%$ step 4 change in methanol feed flowrate as a disturbance. As it can be seen in Figure 12, the control structure is able to reject the disturbance efficiently with a very small over shoot in controlled variables. Furthermore, 6 this shows that the design is least sensitive to the disturbances and has the highest sensitivity to 7 manipulated variables. That is with a very small effort in the manipulated variables, the process is 8 recovered back to its original set-point.
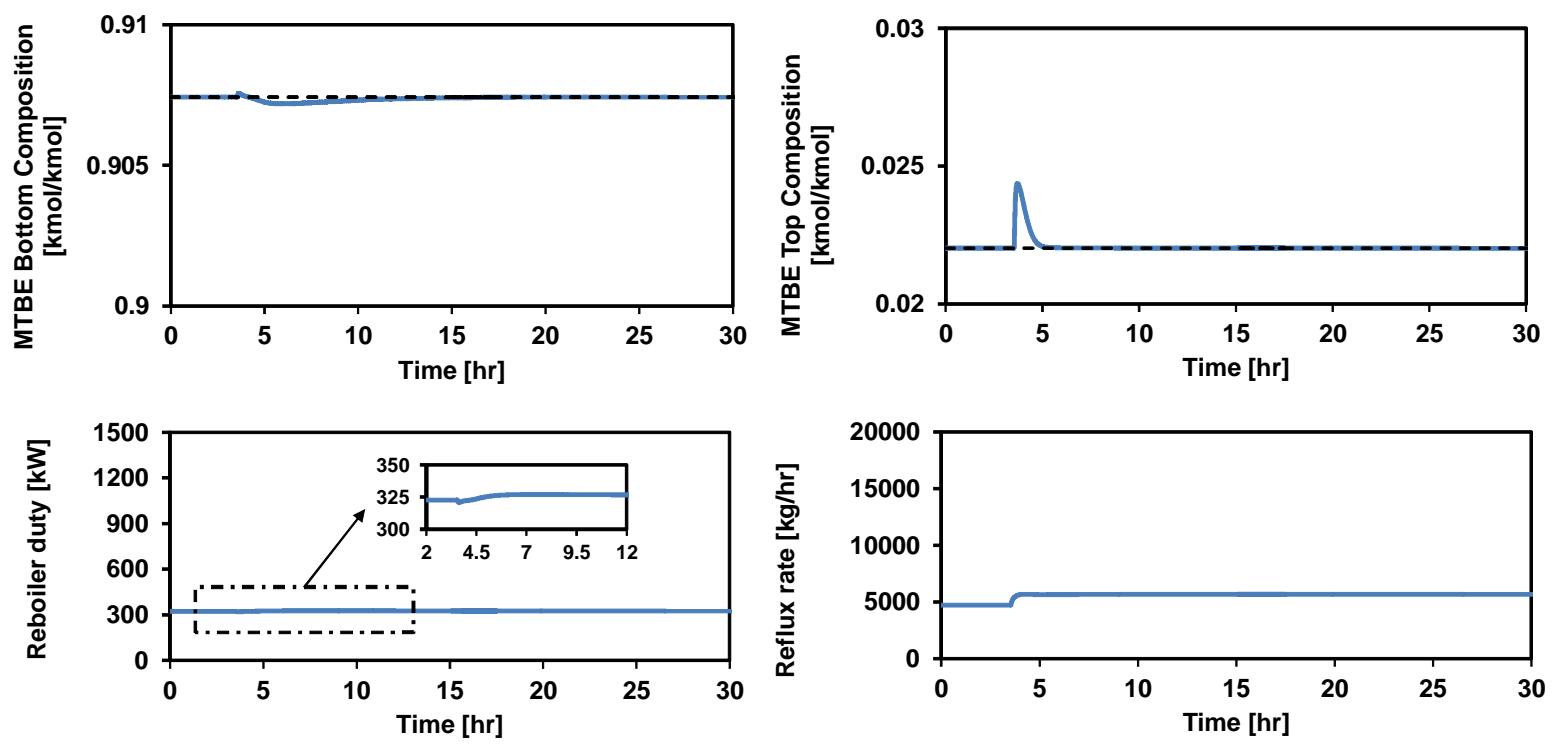

Figure 12: Closed-loop performance of design-control solution to a disturbance in the feed. 
Note that, it can be readily observed from the output of this step of the framework that the process design does take into account the operational and product specifications. Also, the safety issues are not considered because none of the operating conditions correspond to extreme conditions of operation. The driving force based design is obtained to match the product specification and gives the easiest operation (defined by temperature and pressure since the driving force diagram is a function of these variables). Therefore, at the maximum driving force the operation should be safer than any other point.

\subsubsection{Step 5.3: Final selection}

In this step, the values of the terms included in the performance objective function are calculated and presented in Table 4.

Table 4: The values of the terms in performance objective objective function for design-control solution.

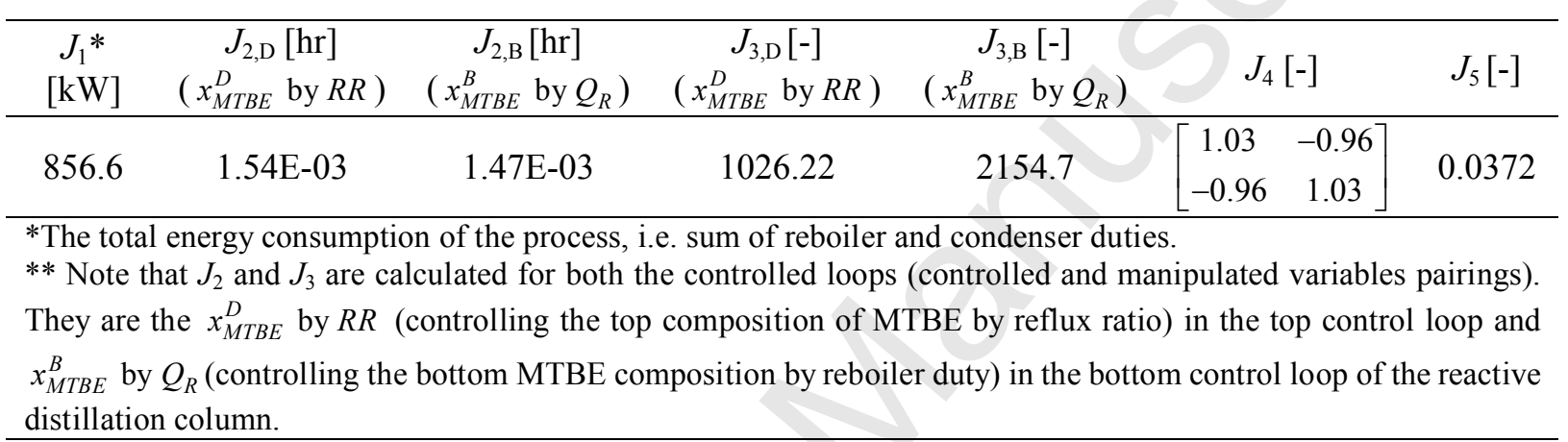

\subsubsection{Further verification of design-control solution using design alternatives which are not at the maximum driving force}

In order to establish the appropriateness of the framework presented in this work, alternative reactive distillation column designs which are not at the maximum driving force are selected for comparison. For purpose of comparison the number of stages needs to be the same for all cases. It would be equivalent if the number of stages is allowed to change but the reflux is kept constant (separation would be feasible for the maximum driving force and infeasible for any other design not using the maximum driving force). Here, the objective is to show the operational cost, then the number of stages needs to be fixed - but the feed locations are changed. Also, for the comparison consistency, here we are using the same control structure as given in Eq. (17) for all the alternatives. The selected design alternatives are summarized in Table 5 .

Table 5: Summary of alternative designs selected for verification as well as design-control solution (see Table 3).

\begin{tabular}{ccccccc}
\hline Design & $\begin{array}{c}\text { Number of } \\
\text { stages }\end{array}$ & $\begin{array}{c}\text { Feed } \\
\text { location }\end{array}$ & $\begin{array}{c}\text { Reflux } \\
\text { ratio }\end{array}$ & $\begin{array}{c}\text { Boilup } \\
\text { ratio }\end{array}$ & $\begin{array}{c}\text { Reboiler duty } \\
(\mathrm{kW})\end{array}$ & $\begin{array}{c}\text { Condenser duty } \\
(\mathrm{kW})\end{array}$ \\
\hline Design-Control Solution & 7 & 4 & 2.83 & 1.27 & 323.3 & 533.3 \\
\hline Alter. 1 & 7 & 2 & 7.0 & 3.9 & 942.5 & 1162.7 \\
Alter. 2 & 7 & 3 & 4.4 & 2.16 & 540.7 & 751.9 \\
Alter. 3 & 7 & 5 & 5.65 & 2.61 & 663.1 & 873.1 \\
\hline
\end{tabular}

The steady-state simulation of all the designs is performed and it is verified that they all satisfy the design targets. Furthermore, Algorithm 4 was applied and RGA and $N_{I}$ are calculated for all the designs given in 
1 Table 5 (these are summarized in Table 6). Next, Algorithm 5 is applied and the closed-loop performance 2 of all the alternatives is evaluated in presence of the same disturbance as for design-control solution. The 3 results of the closed loop performance of the alternatives are given in Figures 13-15.
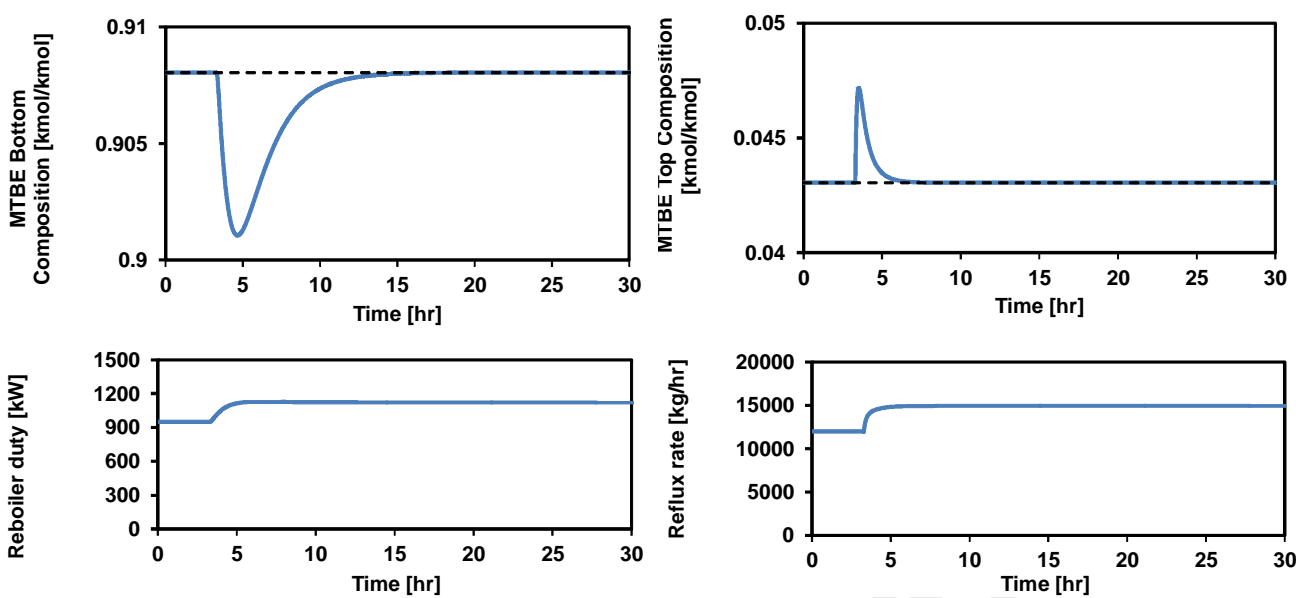

Figure 13: Closed-loop performance of design alternative 1 in presence of a disturbance in the feed.
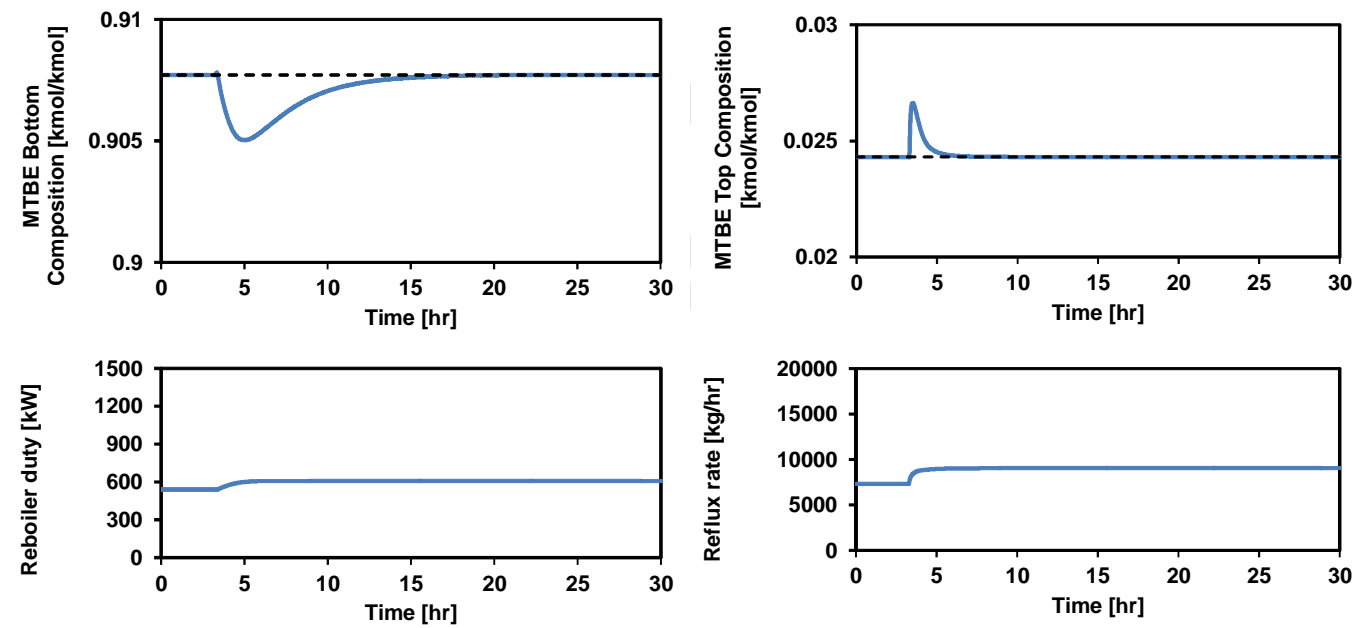

Figure 14: Closed-loop performance of design alternative 2 in presence of a disturbance in the feed. 

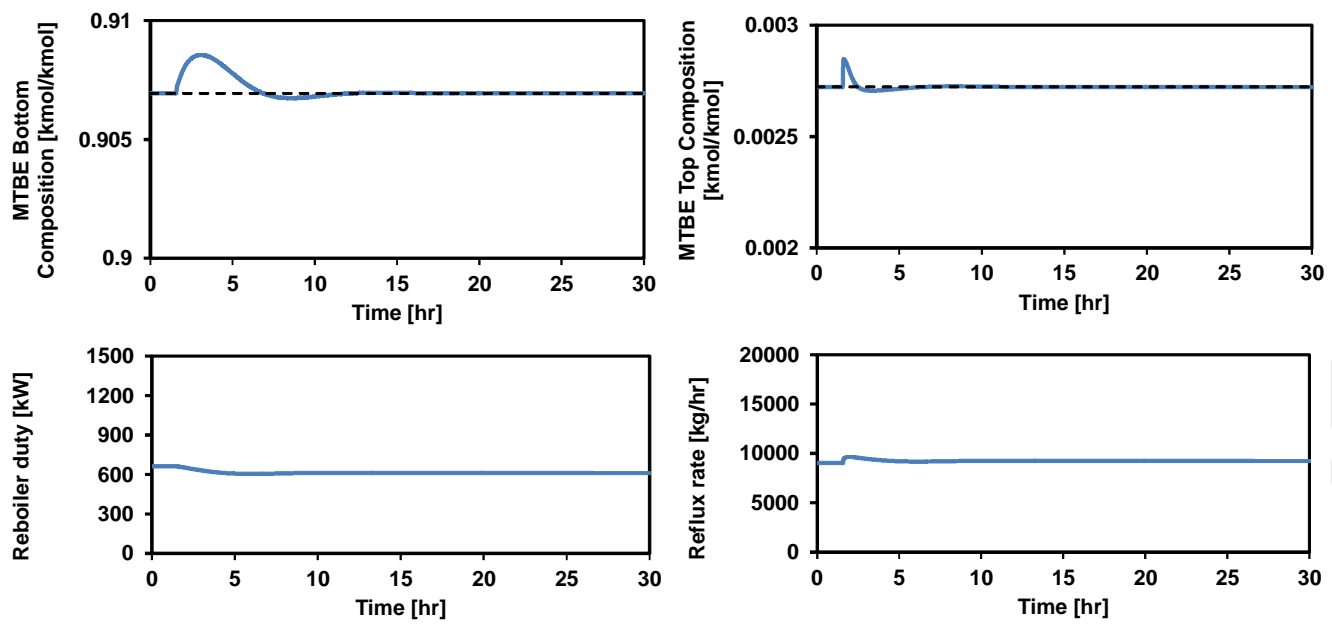

Figure 15: Closed-loop performance of design alternative 3 in presence of a disturbance in the feed.

3

Table 6, presents the values of the performance objective function for all designs including design-control solution. As it is given in Table 6, the design-control solution which corresponds to the reactive distillation column designed at the maximum driving force has the least values of the terms in the objective function both from a steady-state design point of view (nominal energy consumption) and from a control point of view.

Table 6: Summary of the comparison of performance objective function terms for design-control solution and alternative designs.

\begin{tabular}{c|cccc}
\hline Obj. Function Parameter & $\begin{array}{c}\text { Design-control } \\
\text { solution }\end{array}$ & Alter. 1 & Alter. 2 & Alter. 3 \\
\hline$J_{1}^{*}[\mathrm{~kW}]$ & 856.6 & 2112.2 & 1292.6 & 1536.3 \\
\hline$J_{2, \mathrm{D}}[\mathrm{hr}]\left(x_{M T B E}^{D}\right.$ by $\left.R R\right)$ & $1.54 \mathrm{E}-03$ & $3.59 \mathrm{E}-03$ & $1.30 \mathrm{E}-02$ & $5.74 \mathrm{E}-03$ \\
\hline$J_{2, \mathrm{~B}}[\mathrm{hr}]\left(x_{M T B E}^{B}\right.$ by $\left.Q_{R}\right)$ & $1.47 \mathrm{E}-03$ & $2.49 \mathrm{E}-02$ & $1.95 \mathrm{E}-03$ & $1.03 \mathrm{E}-04$ \\
\hline$J_{3, \mathrm{D}}[-]\left(x_{M T B E}^{D}\right.$ by $\left.R R\right)$ & 1026.2 & 2947.1 & 1725.14 & 1212.56 \\
\hline$J_{3, \mathrm{~B}}[-]\left(x_{M T B E}^{B}\right.$ by $\left.Q_{R}\right)$ & 2155 & 44309 & 17744 & 16264 \\
\hline$J_{4}[-]$ & {$\left[\begin{array}{cc}1.03 & -0.96 \\
-0.96 & 1.03\end{array}\right]$} & {$\left[\begin{array}{ccc}-0.29 & 1.29 \\
1.29 & -0.29\end{array}\right]$} & {$\left[\begin{array}{cc}1.34 & -0.34 \\
-0.34 & 1.34\end{array}\right]$} & {$\left[\begin{array}{cc}-1.22 & 2.22 \\
2.22 & -1.22\end{array}\right]$} \\
\hline$J_{5}[-]$ & 0.0372 & -3.447 & 0.7453 & -0.8147 \\
\hline
\end{tabular}

*The total energy consumption of the process, i.e. sum of reboiler and condenser duties.

** Note that $J_{2}$ and $J_{3}$ are calculated for both the controlled loops (controlled and manipulated variables pairings).

They are the $x_{M T B E}^{D}$ by $R R$ (controlling the top composition of MTBE by reflux ratio) in the top control loop and $x_{M T B E}^{B}$ by $Q_{R}$ (controlling the bottom MTBE composition by reboiler duty) in the bottom control loop of the reactive distillation column.

\subsubsection{Application of model predictive controller on the design-control solution}

A model predictive controller (MPC) uses linear plant, disturbance, and noise models to estimate the controller state and predict future plant outputs. Using the predicted plant outputs, the controller solves a quadratic programming optimization problem to determine optimal manipulated variable adjustments. In 
this case, the A, B, and $\mathrm{C}$ matrices of a standard continuous-time state-space model are obtained in Algorithm 4-Step (i) for the design-control solution at the maximum driving force. D matrix is zero. Using the linear model of the process, a MPC-type controller is implemented to perform closed-loop simulations on the design-control solution at the maximum driving force. Here, the plant inputs are: condenser duty $-\mathrm{Q}_{\mathrm{c}}(\mathrm{kW})$, reboiler duty $-\mathrm{Q}_{\mathrm{R}}(\mathrm{kW})$, reflux mass flow rate $-\mathrm{R}(\mathrm{kg} / \mathrm{h})$, distillate mass flow rate - D $(\mathrm{kg} / \mathrm{h})$, bottoms mass flow rate $-\mathrm{B}(\mathrm{kg} / \mathrm{h})$ and the feed molar flow rate $(\mathrm{kmol} / \mathrm{h})$. The plant outputs are: column pressure - P (stage 1), reflux drum liquid level - RLev (m), sump liquid level - SLev (m), mole fraction of MTBE in the distillate $-x \mathrm{D}$ and mole fraction of MTBE in the bottoms $-x \mathrm{~B}$. Figure 16 , presents the MPC implementation on design-control solution and comparison with the MPC implementation on design alternative 1. The disturbance scenario considered in Figure 16 is $+10 \%$ step change in in the total feed flowrate. As it is shown in Figure 16(a), the MPC controller performance is better at the maximum driving force compared to the MPC performance of the design alternative 1 . This is revealed by looking at the controlled variables (the time to reach the set-point) as well as the effort in manipulated variables. 
(a)

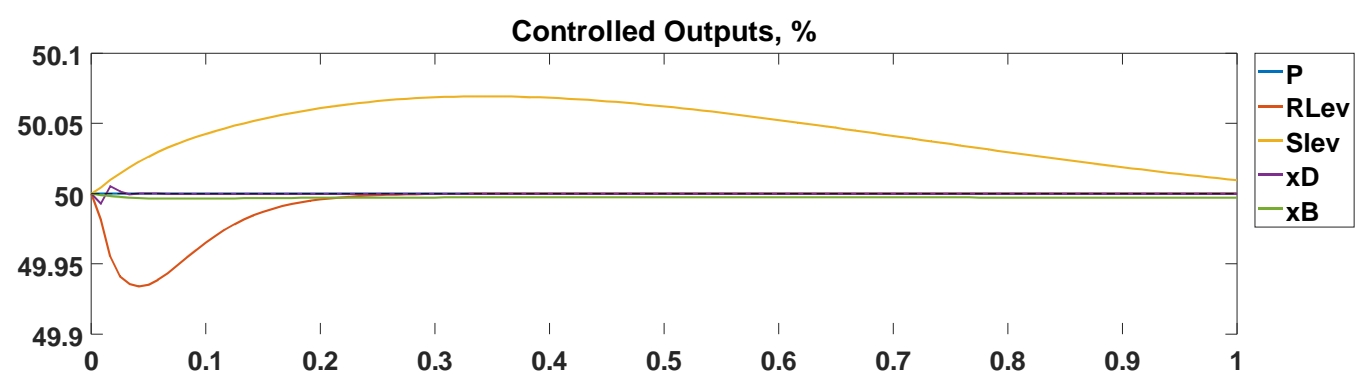

Manipulated Variables, \%

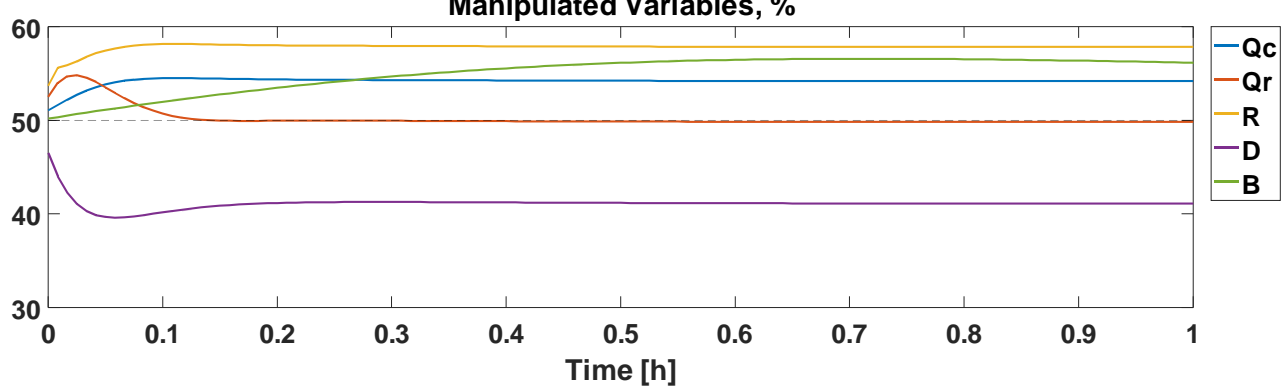

(b)

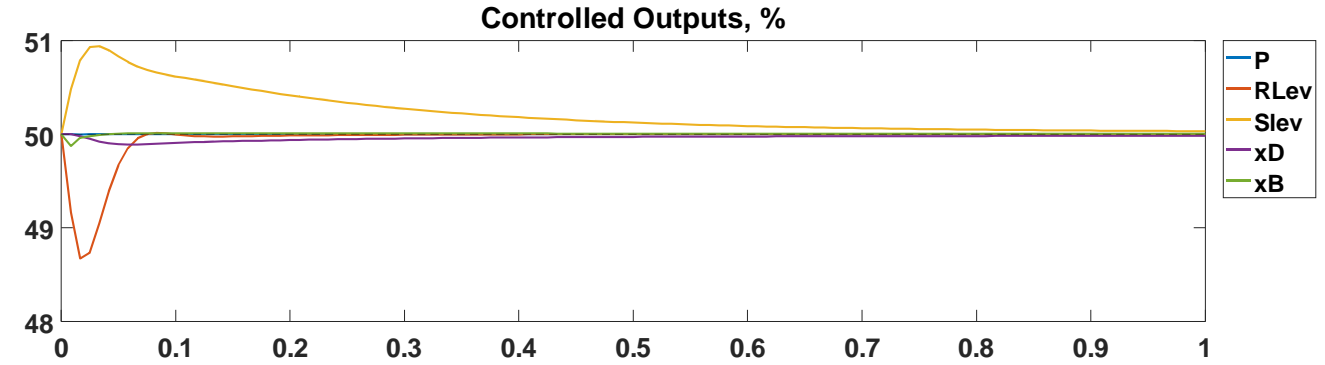

Manipulated Variables, \%

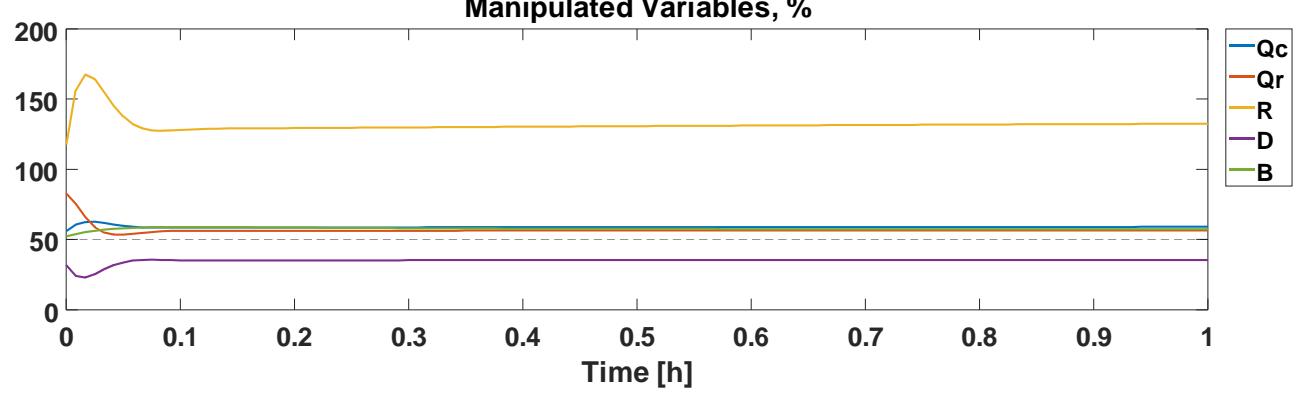

Figure 16: (a) closed-loop performance of the design-control solution, (b) closed-loop performance of design Alternative 1; using MPC implementation in presence of $+10 \%$ step change in total feed flowrate.

3 Figure 17(a), shows the comparison of controlled outputs ( $x \mathrm{D}$ and $x \mathrm{~B})$ using MPC implementation and PI 4 controllers for the design-control solution at the maximum driving force to a $+10 \%$ disturbance in total 5 feed flowrate. It is readily observed from this figure, that the MPC has a better performance compared to 6 the PI controller. However, Figure 17 (b) shows the same comparison for an operating point which is not 7 at the maximum driving force (design alternative 1). Looking at the comparison presented in Figure 17, it 8 can be concluded that the design at the maximum driving force has a better controller performance, 9 regardless of the choice of controller (MPC or PI), compared to any other operating point which is not at 
the maximum driving force. Therefore, it is verified that the design-control solution has a satisfactory performance not only using controllers at the regulatory level, but also advanced control algorithms such as MPC.

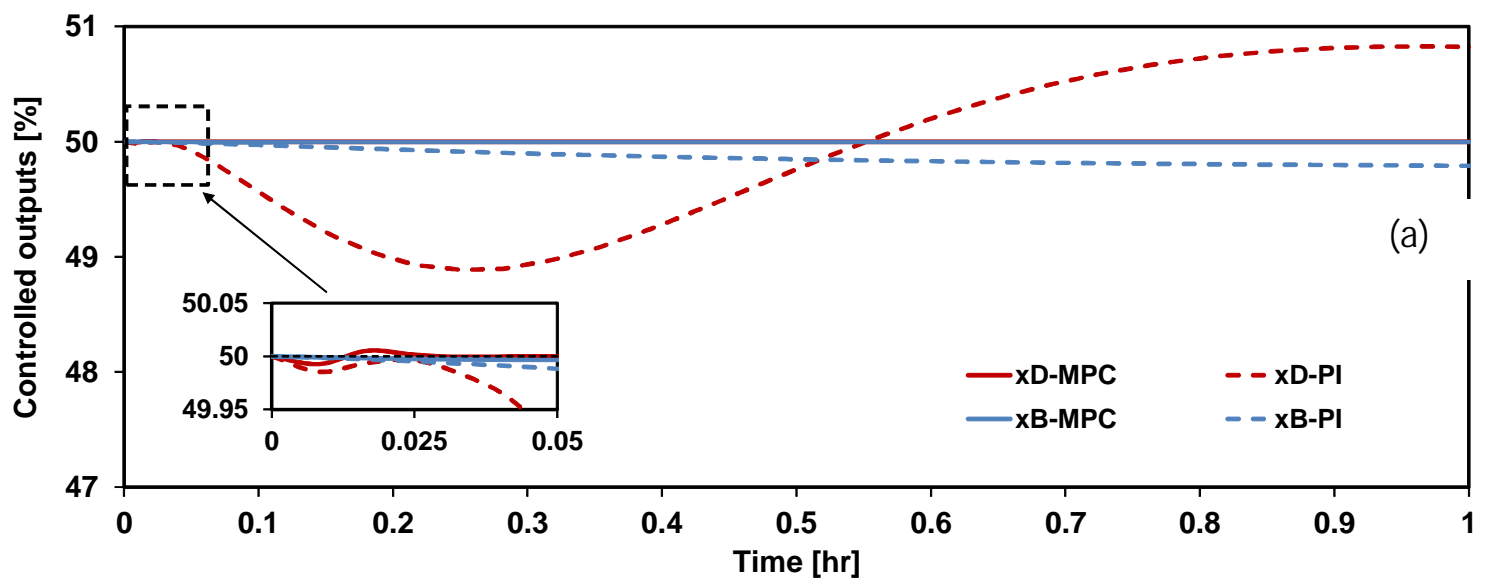

4

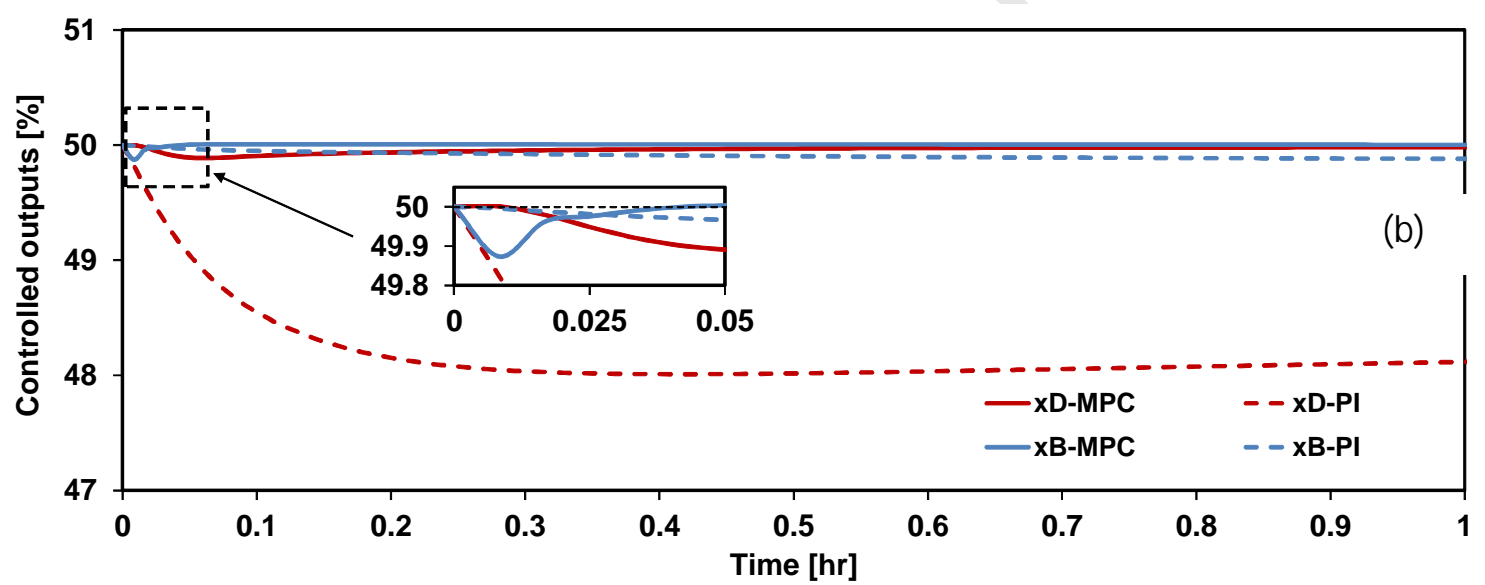

Figure 17: Comparison between controlled outputs $(x \mathrm{D}$ and $x \mathrm{~B})$ of model predictive controller (MPC) and proportional-integral (PI) controllers for (a) the design-control solution operating at the maximum driving force, and (b) the design Alternative 1 (not at the maximum driving force).

\section{Conclusions}

Integrated process design and control of reactive distillation processes that involve multiple elements (more than two) was addressed through a computer-aided framework. The framework facilitates the simultaneous consideration of design and control issues. The proposed framework is generic and can be applied to any reactive distillation process that is represented by multiple elements. A number of algorithms that are similar in concept to design-control of binary non-reactive and binary element reactive distillation processes are used in different steps of the framework. These methods are based on equivalent binary element concept. The application of the framework has been demonstrated through reactive distillation of MTBE with an inert compound. It has been verified through steady-state analysis that the reactive distillation column design-control solution at the maximum equivalent element driving force 
requires the least amount of energy. Furthermore, through analytical and closed-loop simulation it is also verified that the design-control solution has better performance compared to any other design alternative within a fixed design space that is not at the maximum driving force in terms of control structure, disturbance rejection and controllability. Nonetheless, it has been shown that the control of the designcontrol solution at the maximum driving force is not only limited to simple type of controllers such as PI, but also more advanced controllers such as MPC can be used. Therefore, this approach shows that process design can be performed in an easier manner which results in better controllability, operation and energy requirement. The current and future work is to extend the application of the framework to other types of intensified processes, such as membrane-based operations, as well as to process flowsheets and plantwide control. Furthermore, the issues related to uncertainties associated with the model parameters are subject to future works. However, it must be noted that the qualitative results would not be affected - only the quantitative results would be affected in case of uncertainties in the model parameters. That is, the design at the maximum driving force would still be the best, but the steady state values for the controllers may be different.

\section{Acknowledgements}

This article is an original extended version of the work presented at the $11^{\text {th }}$ IFAC Symposium on Dynamics and Control of Process Systems, including Biosystems (DYCOPS-CAB 2016) held during 6-8 June 2016 in Trondheim, Norway; and published in the corresponding IFAC conference proceedings (Mansouri et al., 2016b).

\section{References}

Al-Jarallah, A.M., Lee, A.K.K., Siddiqui, M.A.B., 1988. Kinetics of methyl tertiary butyl ether synthesis catalyzed by sulphuric acid. Chem. Eng. J. 39, 169-174. doi:10.1016/0300-9467(88)80024-8

Alvarado-Morales, M., Hamid, M.K.A., Sin, G., Gernaey, K. V., Woodley, J.M., Gani, R., 2010. A model-based methodology for simultaneous design and control of a bioethanol production process. Comput. Chem. Eng. 34, 2043-2061. doi:10.1016/j.compchemeng.2010.07.003

Babi, D.K., Lutze, P., Woodley, J.M., Gani, R., 2014. A process synthesis-intensification framework for the development of sustainable membrane-based operations. Chem. Eng. Process. Process Intensif. 86, 173-195. doi:10.1016/j.cep.2014.07.001

Bahakim, S.S., Ricardez-sandoval, L.A., 2014. Simultaneous design and MPC-based control for dynamic systems under uncertainty: A stochastic approach. Comput. Chem. Eng. 63, 66-81. doi:10.1016/j.compchemeng.2014.01.002

Bahri, P.A., Bandoni, J.A., Romagnoli, J.A., 2006. Integrated Flexibility and Controllability Analysis in Design of Chemical Processes 43, 997-1015.

Bansal, V., Sakizlis, V., Ross, R., Perkins, J.D., Pistikopoulos, E.N., 2003. New algorithms for mixedinteger dynamic optimization. Comput. Chem. Eng. 27, 647-668. doi:10.1016/S00981354(02)00261-2

Bek-Pedersen, E., Gani, R., 2004. Design and synthesis of distillation systems using a driving-force-based approach. Chem. Eng. Process. Process Intensif. 43, 251-262. doi:10.1016/S0255-2701(03)00120-X

Bristol, E., 1966. On a new measure of interaction for multivariable process control. IEEE Trans. Automat. Contr. 11, 133-134. doi:10.1109/TAC.1966.1098266

Chiu, M. Sen, Arkun, Y., 1991. New result on relative gain array, Niederlinski index and decentralized stability condition: 2x2 plant cases. Automatica 27, 419-421. doi:10.1016/0005-1098(91)90093-H

Chung, Y.-H., Peng, T.-H., Lee, H.-Y., Chen, C.-L., Chien, I.-L., 2015. Design and Control of Reactive Distillation System for Esterification of Levulinic Acid and n -Butanol. Ind. Eng. Chem. Res. 54, 3341-3354. doi:10.1021/ie500660h

Corriou, J.-P., 2004. Process Control Theory and Applications. Springer-Verlog London.

Flores-Tlacuahuac, A., Biegler, L.T., 2007. Simultaneous mixed-integer dynamic optimization for 
integrated design and control. Comput. Chem. Eng. 31, 588-600. doi:10.1016/j.compchemeng.2006.08.010

Francisco, M., Vega, P., Álvarez, H., 2011. Chemical Engineering Research and Design Robust Integrated Design of processes with terminal penalty. Chem. Eng. Res. Des. 89, 1011-1024. doi:10.1016/j.cherd.2010.11.023

Gani, R., Bek-Pedersen, E., 2000. Simple new algorithm for distillation column design. AIChE J. 46, 1271-1274. doi:10.1002/aic.690460619

Grosser, J.H., Doherty, M.F., Malone, M.F., 1987. Modeling of reactive distillation systems. Ind. Eng. Chem. Res. 26, 983-989. doi:10.1021/ie00065a023

Hamid, M.K.A., Sin, G., Gani, R., 2010a. Integration of process design and controller design for chemical processes using model-based methodology. Comput. Chem. Eng. 34, 683-699. doi:10.1016/j.compchemeng.2010.01.016

Hamid, M.K.A., Sin, G., Gani, R., 2010b. Integration of process design and controller design for chemical processes using model-based methodology. Comput. Chem. Eng. 34, 683-699. doi:10.1016/j.compchemeng.2010.01.016

Harmsen, G.J., 2007. Reactive distillation: The front-runner of industrial process intensification. Chem. Eng. Process. Process Intensif. 46, 774-780. doi:10.1016/j.cep.2007.06.005

Hengstebeck, R.J., 1961. Distillation Design. McGraw-Hill, New York.

Hildebrandt, D., Glasser, D., 1990. The attainable region and optimal reactor structures. Chem. Eng. Sci. 45, 2161-2168. doi:10.1016/0009-2509(90)80091-R

Huusom, J.K., 2015. Challenges and opportunities in integration of design and control. Comput. Chem. Eng. 81, 138-146. doi:10.1016/j.compchemeng.2015.03.019

Jantharasuk, A., Gani, R., Górak, A., Assabumrungrat, S., 2011. Methodology for design and analysis of reactive distillation involving multielement systems. Chem. Eng. Res. Des. 89, 1295-1307. doi:10.1016/j.cherd.2011.04.016

Karunanithi, A.T., Achenie, L.E.K., Gani, R., 2005. A New Decomposition-Based Computer-Aided Molecular/Mixture Design Methodology for the Design of Optimal Solvents and Solvent Mixtures. Ind. Eng. Chem. Res. 44, 4785-4797. doi:10.1021/ie049328h

Kookos, I.K., Perkins, J.D., 2001. An Algorithm for Simultaneous Process Design and Control. Ind. Eng. Chem. Res. 40, 4079-4088. doi:10.1021/ie000622t

Lee, H.-Y., Jan, C.-H., Chien, I.-L., Huang, H.-P., 2010. Feed-splitting operating strategy of a reactive distillation column for energy-saving production of butyl propionate. J. Taiwan Inst. Chem. Eng. 41, 403-413. doi:10.1016/j.jtice.2010.03.003

Lenhoff, A.M., Morari, M., 1982. Design of resilient processing plants-I Process design under consideration of dynamic aspects. Chem. Eng. Sci. 37, 245-258. doi:10.1016/0009-2509(82)801590

Mansouri, S.S., Ismail, M.I., Babi, D.K., Simasatitkul, L., Huusom, J.K., Gani, R., 2013. Systematic Sustainable Process Design and Analysis of Biodiesel Processes. Processes 1, 167-202. doi:10.3390/pr1020167

Mansouri, S.S., Sales-Cruz, M., Huusom, J.K., Gani, R., 2016a. Systematic Integrated Process Design and Control of Binary Element Reactive Distillation Processes. AIChE J. doi:10.1002/aic15322

Mansouri, S.S., Sales-Cruz, M., Huusom, J.K., Gani, R., 2016b. Integrated Process Design and Control of Multi-element Reactive Distillation Processes, in: 11th IFAC Symposium on Dynamics and Control of Process Systems, Including Biosystems (DYCOPS-CAB 2016). p. TuB3.2.

Mansouri, S.S., Sales-Cruz, M., Huusom, J.K., Woodley, J.M., Gani, R., 2015. Integrated Process Design and Control of Reactive Distillation Processes. IFAC-PapersOnLine 48, 1120-1125. doi:10.1016/j.ifacol.2015.09.118

McCabe, W.L., Thiele, E., 1925. Graphical design of fractionating columns. Ind. Eng. Chem. 17, 605611. doi:10.1021/ie50186a023

Mehta, S., Ricardez-sandoval, L.A., 2016. Integration of Design and Control of Dynamic Systems under Uncertainty: A New Back-O ff Approach. Ind. Eng. Chem. Res. 55, 485-498. 
doi:10.1021/acs.iecr.5b03522

Michelsen, M.L., 1994. Calculation of multiphase equilibrium. Comput. Chem. Eng. 18, 545-550. doi:10.1016/0098-1354(93)E0017-4

Mohideen, M.J., Perkins, J.D., Pistikopoulos, E.N., 1996. Optimal design of dynamic systems under uncertainty. AIChE J. 42, 2251-2272. doi:10.1002/aic.690420814

Nikačević, N.M., Huesman, A.E.M., Van den Hof, P.M.J., Stankiewicz, A.I., 2012. Opportunities and challenges for process control in process intensification. Chem. Eng. Process. Process Intensif. 52, 1-15. doi:10.1016/j.cep.2011.11.006

Pérez-Cisneros, E.S., 1997. Modelling, Design and Analysis of Reactive Separation Processes. Ph.D. Thesis, Technical University of Denmark, Kongens Lyngby.

Pérez-Cisneros, E.S., Gani, R., Michelsen, M.L., 1997. Reactive separation systems-I. Computation of physical and chemical equilibrium. Chem. Eng. Sci. 52, 527-543. doi:10.1016/S00092509(96)00424-1

Pistikopoulos, E.N., Diangelakis, N.A., 2015. Towards the integration of process design, control and scheduling: Are we getting closer? Comput. Chem. Eng. doi:10.1016/j.compchemeng.2015.11.002

Ricardez-Sandoval, L. a., Budman, H.M., Douglas, P.L., 2009. Application of Robust Control Tools to the Simultaneous Design and Control of Dynamic Systems. Ind. Eng. Chem. Res. 48, 801-813. doi:10.1021/ie800378y

Ricardez-Sandoval, L.A., Budman, H.M., Douglas, P.L., 2009. Integration of design and control for chemical processes: A review of the literature and some recent results. Annu. Rev. Control 33, 158 171. doi:10.1016/j. arcontrol.2009.06.001

Rivera, D.E., Morari, M., Skogestad, S., 1986. Internal model control: PID controller design. Ind. Eng. Chem. Res. 25, 252-265. doi:10.1021/i200032a041

Sánchez-Daza, O., Pérez-Cisneros, E.S., Bek-Pedersen, E., Gani, R., 2003. Graphical and Stage-to-Stage Methods for Reactive Distillation Column Design. AIChE J. 49, 2822-2841. doi:10.1002/aic.690491115

Sanchez-Sanchez, K., Ricardez-Sandoval, L.A., 2013. Simultaneous Process Synthesis and Control Design under Uncertainty: A Worst-Case Performance Approach. AIChE J. 59, 2497-2514. doi:10.1002/aic. 14040

Schrans, S., de Wolf, S., Baur, R., 1996. Dynamic simulation of reactive distillation: An MTBE case study. Comput. Chem. Eng. doi:10.1016/0098-1354(96)00275-X

Seferlis, P., Georgiadis, M.C., 2004. The Integration of Process Design and Control. Comput. Aided Chem. Eng. 17, 1-639.

Sendin, O.H., Moles, C.G., Alonso, A.A., Banga, J.R., 2004. Multi-objective integrated design and control using stochastic global optimization methods, in: Computer Aided Chemical Engineering. pp. 555-581. doi:10.1016/S1570-7946(04)80074-9

Sharifzadeh, M., 2013. Integration of process design and control: A review. Chem. Eng. Res. Des. 91, 2515-2549. doi:10.1016/j.cherd.2013.05.007

Sharma, N., Singh, K., 2010. Control of Reactive Distillation Column: A Review. Int. J. Chem. React. Eng. doi: $10.2202 / 1542-6580.2260$

Skogestad, S., 2003. Simple analytic rules for model reduction and PID controller tuning. J. Process Control 13, 291-309. doi:10.1016/S0959-1524(02)00062-8

Sneesby, M.G., Tade, M.O., Smith, T.N., 1999. Two-point control of a reactive distillation column for composition and conversion. J. Process Control 9, 19-31. doi:10.1016/S0959-1524(98)00007-9

Trainor, M., Giannakeas, V., Kiss, C., Ricardez-sandoval, L.A., 2013. Optimal process and control design under uncertainty: A methodology with robust feasibility and stability analyses. Chem. Eng. Sci. 104, 1065-1080. doi:10.1016/j.ces.2013.10.017

Tuchlenski, A., Beckmann, A., Reusch, D., Düssel, R., Weidlich, U., Janowsky, R., 2001. Reactive distillation - industrial applications, process design \& scale-up. Chem. Eng. Sci. doi:10.1016/S0009-2509(00)00240-2

Wankat, P.C., 2012. Separation process engineering: Includes mass transfer analysis, Third. ed. Prentice 
1

Hall.

Yuan, Z., Chen, B., Sin, G., Gani, R., 2012. State-of-the-art and progress in the optimization-based simultaneous design and control for chemical processes. AIChE J. 58, 1640-1659. doi:10.1002/aic. 13786

\section{Appendix A}

Additional conditions for reactive distillation column design at the maximum driving force.

a) If condition 1a is satisfied, then relocate NF between $5 \%$ and $10 \%$ up in the column.

Else, if condition $1 \mathrm{~b}$ is satisfied, then relocate NF between $5 \%$ and $10 \%$ down in the column.

b) If condition $2 \mathrm{a}$ is satisfied then relocate NF $10 \%$ down.

Else, if condition $2 b$ is satisfied, then relocate NF 5\% down.

Else, if condition $2 \mathrm{c}$ is satisfied, then relocate NF $5 \%$ up.

Else, if condition $2 \mathrm{~d}$ is satisfied, then relocate $\mathrm{NF} 10 \%$ up.

\begin{tabular}{cl}
\hline Condition 1 & \\
\hline a) & $W_{H K, z}<0.8$ and $D_{x}<0.7$ \\
b) & $W_{H K, z}<0.8$ and $D_{x}>0.3$ \\
\hline Condition 2 & $\frac{1-W_{L K, D}}{1-W_{H K, B}}<0.01$ and $D_{x}<0.7$ \\
a) & $\frac{1-W_{L K, D}}{1-W_{H K, B}}<0.1$ and $D_{x}<0.7$ \\
b) & $\frac{1-W_{H K, B}}{1-W_{L K, D}}<0.1$ and $D_{x}>0.3$ \\
c) & $\frac{1-W_{H K, B}}{1-W_{L K, D}}<0.01$ and $D_{x}>0.3$ \\
d) &
\end{tabular}

